\title{
Channelling of high-latitude boundary-layer flow
}

\author{
N. Nawri and R. E. Stewart \\ Department of Atmospheric and Oceanic Sciences, McGill University, Montreal, Canada
}

Received: 24 August 2007 - Revised: 14 December 2007 - Accepted: 21 December 2007 - Published: 31 January 2008

\begin{abstract}
Due to the stability of the boundary-layer stratification, high-latitude winds over complex terrain are strongly affected by blocking and channelling effects. Consequently, at many low-lying communities in the Canadian Archipelago, including Cape Dorset and Iqaluit considered in this study, surface winds for the most part are from two diametrically opposed directions, following the orientation of the elevated terrain. Shifts between the two prevailing wind directions can be sudden and are associated with geostrophic wind directions within a well defined narrow range. To quantitatively investigate the role of large-scale pressure gradients and the quasi-geostrophic overlying flow, an idealised dynamical system for the evolution of channelled surface winds is derived from the basic equations of motion, in which stability of stationary along-channel wind directions is described as a function of the geostrophic wind. In comparison with long-term horizontal wind statistics at the two locations it is shown that the climatologically prevailing wind directions can be identified as stationary states of the idealised wind model, and that shifts between prevailing wind directions can be represented as stability transitions between these stationary states. In that sense, the prevailing local wind conditions can be interpreted as attracting states of the actual flow, with observed surface winds adjusting to a new stable direction as determined by the idealised system within 3$9 \mathrm{~h}$. Over these time-scales and longer it is therefore advantageous to determine the relatively slow evolution of the observationally well-resolved large-scale pressure distribution, instead of modelling highly variable surface winds directly. The simplified model also offers a tool for dynamical downscaling of global climate simulations, and for determining future scenarios for local prevailing wind conditions. In particular, it allows an estimation of the sensitivity of local lowlevel winds to changes in the large-scale atmospheric circulation.
\end{abstract}

Correspondence to: N. Nawri

(nawri@meteo.mcgill.ca)

\section{Introduction}

Strong and variable surface wind conditions are among the main weather hazards in the Arctic. They cause dangerous flying conditions, significant low-level visibility reduction in blowing snow and, through snow accumulation, may block roads and bury entire buildings. Near the coast, where most communities are located, strong and variable surface winds often have a significant impact on sea state and sea ice conditions, affecting again important transport and travel routes. Due to these hazardous impacts there are concerns about changing prevailing local wind conditions in the context of global environmental change. Already, vulnerabilities and limits to adaptive capacity due to stronger and more variable surface wind conditions have been identified in some communities of Canada's Nunavut Territory (Ford et al., 2006a; Ford et al., 2006b; Henshaw, 2006; Laidler and Elee, 2006).

The prevailing surface wind, and to some degree general weather conditions, at many Arctic communities are affected not only by the proximity to the sea, but also by the surrounding terrain. As a result, orographic modification of low-level winds and particularly blocking and channelling effects on stably stratified flow are noticeable in the prevailing wind conditions at many locations of the Canadian Arctic (Hudson et al., 2001), such that surface winds for the most part are from two diametrically opposed directions, and shifts between the two prevailing wind directions can be sudden. In that context, channelling refers to flow conditions under which wind directions are approximately perpendicular to the local elevation gradient.

Due to the sparse available data, detailed modelling of the wind field at specific high-latitude locations is not practicable on an operational basis, particularly over complex terrain. Given the importance of strong and variable surface winds across the Arctic, the goal of this study therefore is to develop a simple conceptual model for stably stratified orographic boundary-layer flow, which can be implemented for shortterm local wind forecasting and downscaling of large-scale climate predictions more easily than high-resolution numerical simulations. Thereby, the focus is on large-scale driven

Published by Copernicus Publications on behalf of the European Geosciences Union and the American Geophysical Union. 

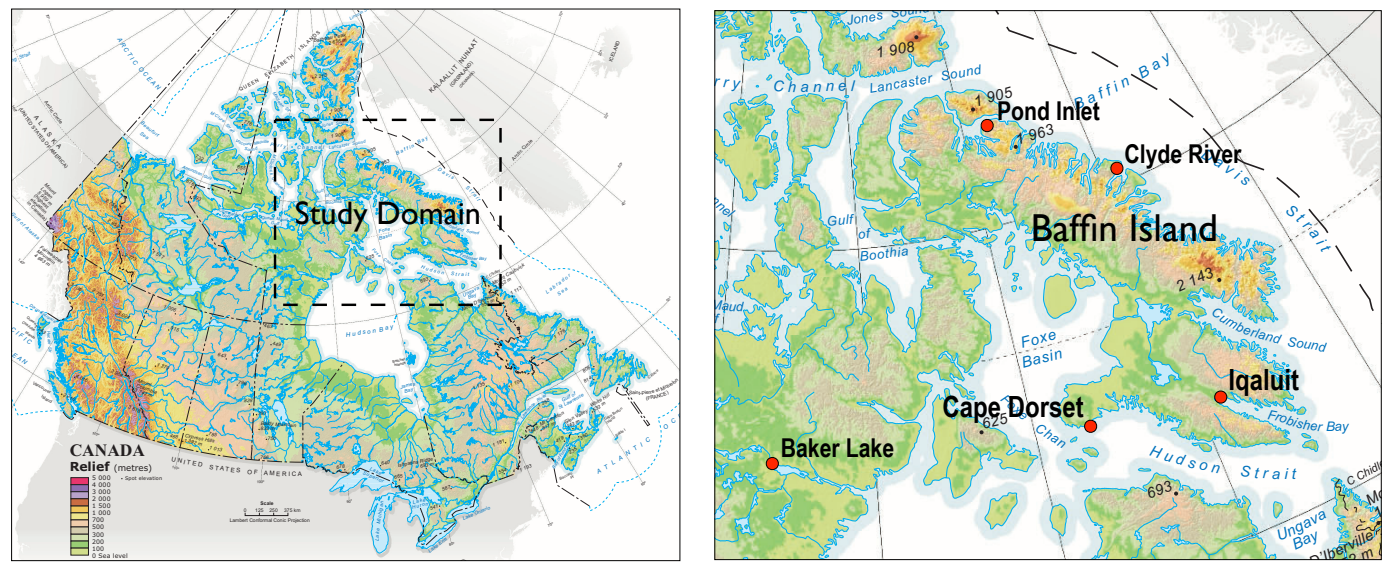

Fig. 1. Study domain and locations of interest for this study. The dashed rectangle on the left indicates the boundaries of the expanded map on the right. Topographic base maps obtained from Natural Resources Canada.

flow channelled between two approximately parallel orographic barriers, such as within valleys or fjords, and on sudden shifts between along-channel wind directions.

Previously, Gross and Wippermann (1987) showed that even in the broad Upper Rhine Valley of Germany with modest local relief, large-scale pressure-driven channelling may be the dominant forcing mechanism under stable wintertime conditions. Statistically, shifts between channelled wind directions in that area therefore occur with approximately along-valley geostrophic wind directions. Under those circumstances the low-level flow within the valley may have a significant component opposite to the overlying quasigeostrophic flow. By means of numerical simulations, the authors also showed that under stable conditions an alongvalley jet below ridge-top level can form if the geostrophic wind is steady and perpendicular to the predominant orientation of the valley. The relative role of large-scale pressure gradients in comparison with other forcing mechanisms in the broad Tennessee Valley of the United States was investigated by Whiteman and Doran (1993), who found that large-scale pressure-driven channelling is the dominant forcing mechanism under conditions of weak and intermediate overlying winds. For strong ambient winds, downward momentum transfer was also found to be important under conditions of weak static stability. Eckman (1998) showed that within the same valley pressure-driven channelling at night is concentrated on the leeward side of the valley relative to the overlying flow, and is weaker in the afternoon. As in the Rhine Valley, due to the importance of unbalanced large-scale pressure gradients under stable conditions, alongvalley winds shift directions with approximately along-valley geostrophic winds, and may have a significant component opposite to the overlying flow. Similarly, Reid (1996) showed that large-scale pressure gradient forces can lead to highly ageostrophic channelled surface winds within Cook Strait between the North and South Island of New Zealand. However, in contrast with these observations, Furger (1992) showed that at Payerne, between the Jura Mountains and the Swiss Alps, shifts between channelled surface wind directions statistically occur with overlying wind directions approximately perpendicular to the predominant orientation of the valley. This suggests that under those circumstances coupling of different layers and turbulent momentum transfer from the overlying flow also plays an important role. As a result, the ageostrophic component of channelled flow is minimised. Weber and Kaufmann (1998) compared the relative importance of different forcing mechanisms for channelled flows in several Alpine valleys. They found that local wind conditions under the influence of essentially the same overlying flow can vary significantly between nearby locations, and are determined by differences in the local terrain, such as valley orientation, length, width, and depth. In particular, they found that winds in narrow valleys with widths of about 2$3 \mathrm{~km}$ are more strongly affected by regional temperature gradients than in wider valleys. Also, in short and narrow valleys and with strong overlying flow, downward momentum transfer dominates the large-scale pressure gradient force. Based on measurements in the American Grand Canyon, the significance of large-scale pressure gradients for the forcing of winds in a mid-latitude valley under stable (wintertime) conditions relative to local thermal effects was also discussed by Whiteman et al. (1999). The dependence of mid-latitude valley flow on static stability was also shown by Klaus et al. (2003), who studied diurnal variations in near-surface wind directions within the Baar Basin of Germany, related to the varying importance of large-scale pressure gradients, local thermal forcing, and downward turbulent momentum transfer. In the presence of more complex terrain, such as within a bifurcating valley, splitting of channelled flow may occur (Drobinski et al., 2001; Drobinski et al., 2006).

These previous studies clearly demonstrate the phenomenological complexity of channelled valley flows. Variations in the large-scale atmospheric conditions, as well as local differences in the boundary-layer stratification and 

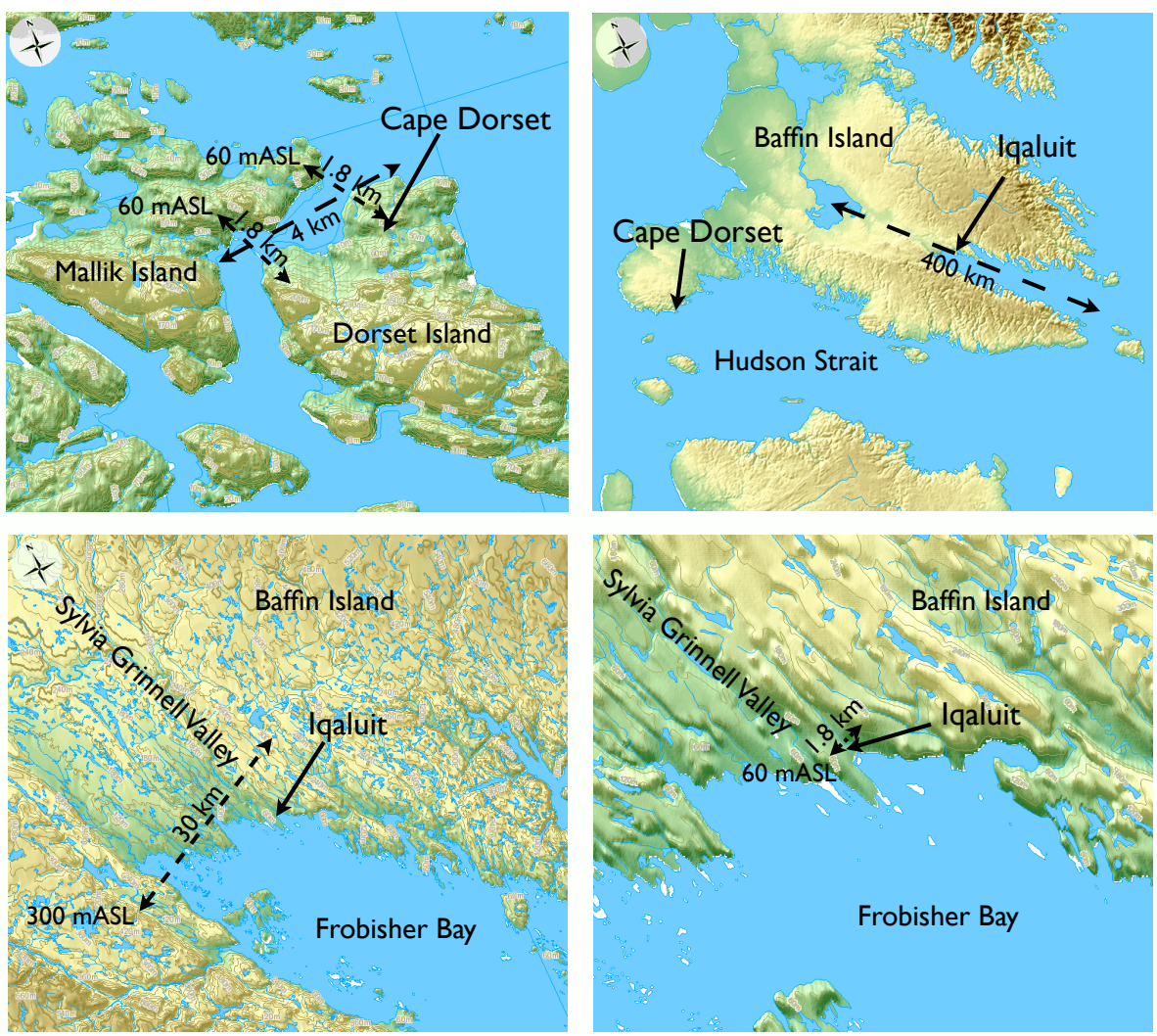

Fig. 2. Geographical conditions around Cape Dorset and Iqaluit. At each location, the solid arrow indicates the position of the wind sensor. Both ends of the cross-channel dashed arrows are at the same elevation as indicated. Topographic base maps obtained from Natural Resources Canada.

geographical setting, may lead to different force balances at different locations or in different seasons. In this study, to quantitatively investigate the role of large-scale pressure gradients in the forcing of orographic flow, and to derive criteria for the occurrence of strong winds and sudden wind shifts, a simple parameterised model for channelled surface winds is therefore derived from the basic equations of motion, which can be implemented based only on available operational surface data. It is shown that the empirical model captures the prevailing surface wind conditions at locations with diametrically opposed prevailing wind directions. Since it only depends on the local wind statistics and large-scale pressure gradients, the model provides a unified mathematical framework for the description of prevailing surface wind conditions at locations with greatly different geographical conditions.

The validity of model predictions is tested based on the wind conditions at Cape Dorset $\left(76.530^{\circ} \mathrm{W}, 64.230^{\circ} \mathrm{N}\right)$ and Iqaluit $\left(68.545^{\circ} \mathrm{W}, 63.747^{\circ} \mathrm{N}\right.$ ) (see Figs. 1 and 2). The meteorological observation sites at the two locations are situated at 50 and $34 \mathrm{~m}$ above sea level (mASL), respectively. Both locations are at the coast on or near southern Baffin Island in the eastern Canadian Arctic, and are separated by about $400 \mathrm{~km}$ in east-west direction. They are in a regioncharacterised by a very diverse storm activity and by storms following several different prevailing tracks (Hudson et al., 2001). Although the local impacts may be very different, they are essentially affected by the same storm systems. At both locations channelling, strong surface winds, and sudden wind shifts occur regularly.

The article is organised as follows. Section 2 describes the data used in this study. Section 3 discusses climatological characteristics of surface winds at Cape Dorset and Iqaluit, relevant for the discussion in later sections. The equations of motion and the dynamical formalism on which the simplified model is based are introduced in Sect. 4. Section 5 then describes the various simplifications and parameterisations used in the derivation of the local wind model. The dynamic properties of the local wind model, such as the stability of stationary wind directions, are discussed in Sect. 6, whereas Sect. 7 discusses shifts between stationary wind directions. The large-scale weather patterns typically associated with extended periods of channelled wind conditions are briefly discussed in Sect. 8, and Sect. 9 introduces a simple model for the evolution of surface wind speed during these extended periods of channelled winds. The main results are then summarised in Sect. 10. 


\section{Data}

The data used in this study are routine hourly surface measurements of atmospheric pressure, temperature, and horizontal wind speed and direction at Cape Dorset and Iqaluit, as well as 12-hourly soundings of wind direction at Iqaluit.

Hourly values of speed and direction of the horizontal surface wind are $2 \mathrm{~min}$ averages measured at $10 \mathrm{~m}$ above the ground. Surface pressure and temperature are represented by instantaneous values measured at $1.5 \mathrm{~m}$ above the ground. Following the procedure described in Nawri and Stewart (2006), surface geostrophic winds are calculated using additional surface pressure data at Pond Inlet and Baker Lake for Cape Dorset, and at Clyde River and Cape Dorset for Iqaluit. The directions of the actual and geostrophic wind are rounded to the nearest 10 degrees.

Since continuous hourly measurements at Cape Dorset and Clyde River are only available since 1985, the study is restricted to the 22-year period from 1985 through 2006. During that period, at all locations there are less than $3 \%$ missing hourly surface data for all variables. These missing data are linearly interpolated, except for wind direction, for which a nearest neighbour interpolation is used.

Only those soundings of wind direction with at least 25 valid data values are considered. Using nearest neighbour interpolation, all valid soundings are transferred onto a regular vertical grid with values at 44 (level of surface wind), 50 and $75 \mathrm{mASL}$, and at each $50 \mathrm{~m}$ upward from $100 \mathrm{mASL}$.

\section{Climatological features of channelled surface winds}

This section briefly introduces some climatological features of the surface wind conditions at Cape Dorset and Iqaluit. A special emphasis is on channelled winds, i.e., winds directed along the local orientation of orographic channels such as valleys and fjords, or between two islands. As shown in Fig. 2, these are winds following the east-west orientation of the channel between Mallik and Dorset Islands at Cape Dorset, and the northwest-southeast orientation of Sylvia Grinnell Valley and Frobisher Bay at Iqaluit.

Aside from differences in the orientation of channels, the geographical conditions vary greatly between the two locations. With a typical ridge-top level of $60 \mathrm{mASL}$ at Cape Dorset and of $600 \mathrm{mASL}$ at Iqaluit, there is a factor of ten between the overall channel depths. Due to the complexity of the terrain, the channel widths are harder to compare. Given only wind observations over a single point at both locations, it is impossible to determine the horizontal extent of channelled flow in cross-channel direction. Due to the overall low terrain elevation at Cape Dorset, the relevant height for the modification of surface winds at the measurement site is likely to be the typical ridge-top level on both sides of the channel. At an elevation of $60 \mathrm{mASL}$, large variations in channel width occur, but near the wind sensor, the channel is $1.8 \mathrm{~km}$ wide. At Iqaluit, the relevant terrain height for the modification of surface winds is likely to be less than ridgetop level. Based on sounding data, the directional vertical shear strongly depends on wind direction and speed, as well as the temperature stratification (Nawri and Stewart, 2006). However, on average, at half ridge-top level (300 mASL), wind directions are still within 20 degrees of the prevailing surface wind directions. At that height, the elevated terrain towards the northeast and southwest of the community are separated by about $30 \mathrm{~km}$. Considering the situation at Cape Dorset, it is quite possible that the relevant terrain height is even less. In that case, the relevant width of the channel also decreases, being $1.8 \mathrm{~km}$ at a terrain elevation of $60 \mathrm{mASL}$ near the wind sensor. Unlike at Cape Dorset, however, there is a systematic narrowing of the channel towards the northwest, and a sudden widening towards the southeast, without changes in the prevailing orientation of the terrain. The uncertainties in the relevant terrain height also complicate the estimation of the relevant channel lengths. Taking into account the entire length of the elevated terrain on southern Baffin Island with a consistent northwest-southeast orientation, there is a factor of hundred between the approximate lengths of the channels.

Additionally there are differences in the configuration of land masses and water bodies. Whereas at Iqaluit land-sea differences exist mainly in along-channel direction, in the vicinity of Cape Dorset the coastline is oriented in alongas well as cross-channel directions. However, despite these significant differences in the orientation and size of the orographic channels, it is shown in this section that qualitatively similar wind conditions are observed at the two locations, as well as similar relationships between actual and geostrophic surface wind directions.

Given these similarities and the uncertainties associated with the relevant channel geometry, reference cannot be made to specific length scales for the development of a simplified wind model. In particular, this excludes scale analyses of the dynamical equations. Instead, statistical relationships will be used based on the climatological conditions introduced in this section.

Due to the predominantly stable stratification of the highlatitude atmospheric boundary-layer, even modest terrain, as at the two locations considered here, can have a strong impact on local surface wind conditions. More specifically, at both locations surface winds are significantly affected by channelling effects. As seen in Fig. 3, in contrast with the surface geostrophic wind direction, actual wind directions at Cape Dorset and Iqaluit are essentially bi-directional and diametrically opposed, such that the two prevailing wind directions coincide with the local orientation of the terrain. However, due to the location of the wind sensor at the centre of the orographic channel, as well as the greater height and consistent orientation of the terrain over a larger area, the channelling efficiency at Iqaluit is higher than that at Cape Dorset. This may also in part be due to the fact that at Cape Dorset the wind sensor is near the top of the local terrain peaks. 
To quantitatively study channelling efficiency, wind directions are separated into 50-degree sectors $S_{1}$ and $S_{2}$ around the primary and secondary prevailing wind directions, respectively. Consequently, sector $S_{1}$ covers the range of 255304 degrees around west at Cape Dorset and of 295-344 degrees around northwest at Iqaluit, whereas sector $S_{2}$ covers the range of 75-124 degrees around east at Cape Dorset and of 115-164 degrees around southeast at Iqaluit. Since the wind sensor at Cape Dorset is near the eastern end of the channel, channelling effects there are mainly noticeable with westerly surface winds. Overall, $51 \%$ of all but calm surface winds are within the sectors $S_{1}$ and $S_{2}$. In comparison, $69 \%$ of all but calm surface winds at Iqaluit are within either $S_{1}$ and $\mathrm{S}_{2}$. For strong winds of at least $10 \mathrm{~m} \mathrm{~s}^{-1}$ channelling efficiency is higher at both locations, with $58 \%$ at Cape Dorset and $84 \%$ at Iqaluit. There are also differences in the relative occurrence of the two diametrically opposed prevailing wind directions. At Cape Dorset, the occurrence of easterly winds is $46 \%$ of that of westerly winds, whereas the occurrence of southeasterly winds at Iqaluit is $64 \%$ of that of northwesterly winds.

Referring again to Fig. 3, at both locations transitions between the prevailing wind directions climatologically occur with approximately cross-channel surface geostrophic wind directions from north-northeast and south-southwest at Cape Dorset, and from east-northeast and west-southwest at Iqaluit. This suggests that at both locations local surface wind directions are significantly influenced by the large-scale surface pressure distribution. In fact, there appears to be the same relative relationship between actual and geostrophic surface wind directions: both, the prevailing surface wind directions as well as the critical surface geostrophic wind directions are simply rotated by 45 degrees, when compared between the two locations, together with the local orientation of the terrain. The absence of significant net thermal effects within the narrow channel at Cape Dorset is in contrast with the conditions within Alpine valleys of similar widths (Weber and Kaufmann, 1998). This can probably be explained by the difference between a maritime channel between two islands and a valley, as well as by the shallow depth of the channel at Cape Dorset.

At Cape Dorset, sounding data are not available that would allow a comparison between surface geostrophic wind directions and actual wind directions at different vertical levels. However, as shown in Fig. 4, at Iqaluit there is a good correlation between the surface geostrophic wind direction $\phi_{g}$ and the direction $\phi$ of the actual wind at ridge-top level, which is at about $600 \mathrm{mASL}$. Deviations $\Delta \phi=\phi_{g}-\phi$ between the two variables, reduced to the half-open interval of $(-180,180)$ degrees, are unsystematically positive or negative, and for the most part less than 45 degrees. In fact, as seen in Fig. 5, the root-mean-squared (RMS) deviations of actual wind directions at each vertical level from the corresponding surface geostrophic wind directions at Iqaluit attains a minimum at or near ridge-top level. Deviations at ridge-top level are (a)

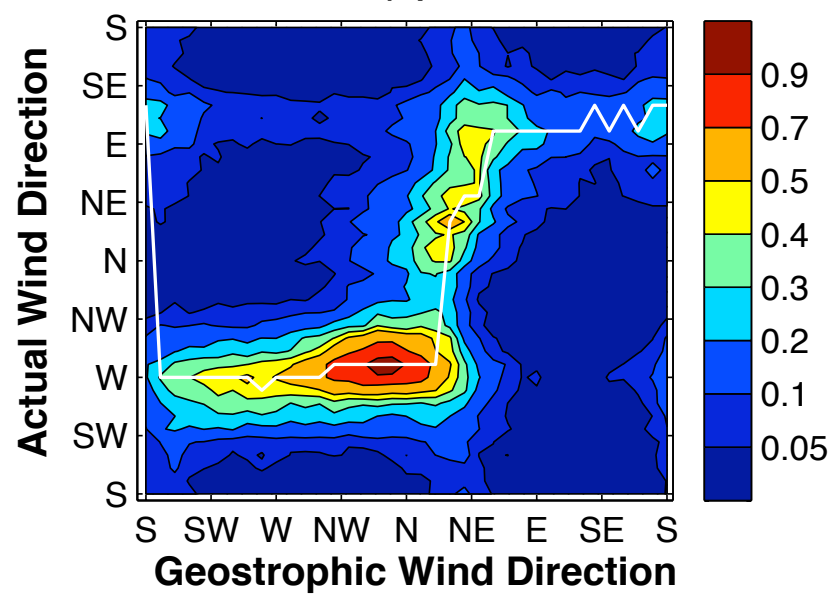

(b)

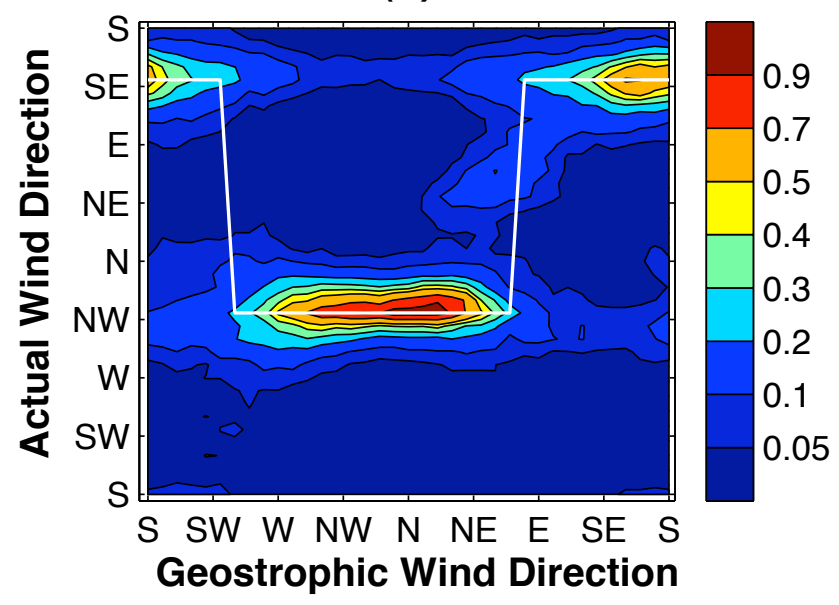

Fig. 3. Joint normalised occurrence of actual and geostrophic surface wind directions (total occurrence within the data period, divided by the occurrence of the most frequent combination of actual and geostrophic wind directions)at (a) Cape Dorset, and (b) Iqaluit. The white line connects the most frequently occurring wind directions for each geostrophic wind direction.

particularly small for the two along-channel surface wind directions. Under all surface wind conditions, RMS deviation rapidly decreases away from the surface as the wind within the orographic channel adjusts to the geostrophic balance at ridge-top level. The increase in RMS deviation above ridgetop level is due to large-scale baroclinicity and changes with height of the geostrophic wind itself.

Surface geostrophic wind can therefore be taken as an approximation of the actual flow just above ridge-top level. It can then be seen from Fig. 3 that, in addition to a close connection with large-scale pressure gradients, local surface wind directions are also strongly affected by the flow immediately above the elevated terrain through downward turbulent momentum transfer. As far as the prevailing wind conditions are concerned, these two external forcing mechanisms related to the larger-scale atmospheric circulation dominate 


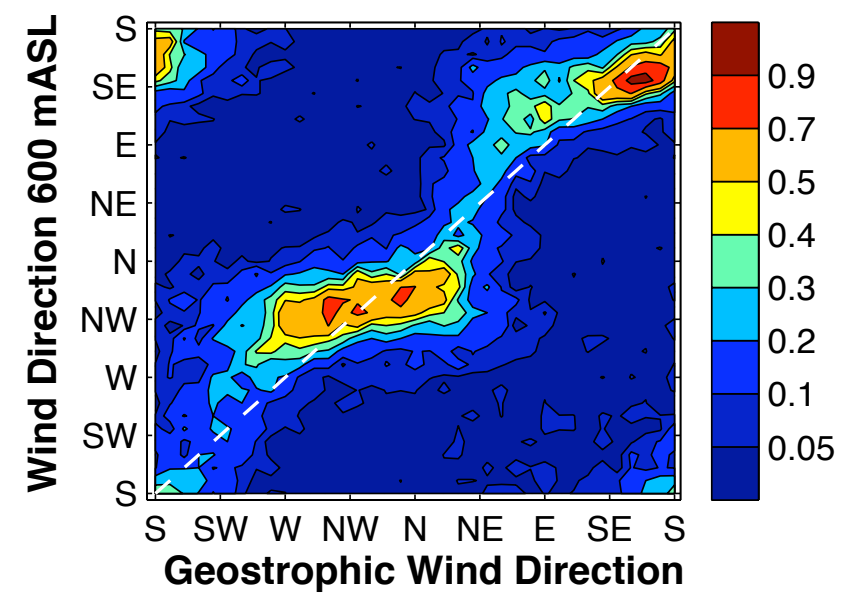

Fig. 4. Joint normalised occurrence of surface geostrophic wind directions and actual wind directions at ridge-top level (600 mASL) at Iqaluit. The dashed white line represents geostrophic wind directions.

over local boundary-layer forcing, such as thermally generated pressure gradients within the orographic channel. The effects of the large-scale forcing mechanisms will be discussed in more detail in later sections.

As shown in Fig. 6, channelling effects at both locations can also be seen in the mean hourly wind direction tendency as a function of local surface wind conditions. Especially at Iqaluit the strong influence of the surrounding topography is noticeable. Based on mean wind direction tendencies, there are two stable equilibria for along-channel winds from northwest and southeast, coinciding with the prevailing wind directions, and two unstable equilibria for cross-channel winds from northeast and southwest. At Cape Dorset there also is a well defined stable equilibrium for the dominant westerly wind direction. However, the secondary prevailing wind direction from east is only weakly defined based on mean hourly wind direction tendencies.

Figure 7 shows the hourly ensemble mean evolution of various surface variables at Cape Dorset and Iqaluit during extended periods of channelled wind conditions. Ensembles include all $24-\mathrm{h}$ periods within the study period during which wind direction consistently was within either sector $S_{1}$ or $S_{2}$, and during which wind direction for at least the previous three hours was outside the respective sector. The mean evolution of surface variables during these extended periods of channelled winds for the most part is similar at the two locations. On average, surface wind speed, especially at Iqaluit, initially increases during channelled wind conditions, reaching maxima after about $12 \mathrm{~h}$ with the primary prevailing wind direction, and weaker maxima after about $16 \mathrm{~h}$ with the secondary prevailing wind direction. With mean annual surface wind speeds, excluding calm conditions, of $5.3 \mathrm{~m} \mathrm{~s}^{-1}$ at Cape Dorset and $5.0 \mathrm{~m} \mathrm{~s}^{-1}$ at Iqaluit, wind speeds during extended periods of channelled flow, except initially during southeasterly winds at Iqaluit, are well above average. For comparison, mean annual surface geostrophic wind speeds are $7.1 \mathrm{~m} \mathrm{~s}^{-1}$ at Cape Dorset and $8.3 \mathrm{~m} \mathrm{~s}^{-1}$ at Iqaluit. Initially, extended periods of channelled wind conditions are therefore associated with above average horizontal largescale pressure gradients. However, for the primary prevailing wind directions pressure gradients gradually weaken, resulting in supergeostrophic surface winds after about $12 \mathrm{~h}$ at both locations. Therefore, at both locations, stationary wind directions are associated with significant changes in wind speed. In fact, as seen in Sect. 6, acceleration is related to the stability of stationary wind directions. Atmospheric conditions leading to stationary along-channel wind directions are therefore also conducive to positive acceleration. At Iqaluit, in comparison with Cape Dorset, the stronger acceleration of channelled surface winds and the greater stability of alongchannel wind directions is in part due to stronger geostrophic winds.

On average, $\Delta \phi$ at both locations is positive and larger for the primary than for the secondary prevailing wind direction. Generally, these winds therefore have a significant component towards lower pressure, which, together with the initially strong large-scale pressure gradients, may be related to the generally high wind speeds and the increase in wind speed during the first half of the period. After about $12 \mathrm{~h}$, easterly winds at Cape Dorset are typically directed towards higher pressure. Other forcing mechanisms such as downward momentum transfer from the overlying flow must therefore be active to maintain the high wind speeds.

Due to the higher ground elevation, the surface pressure at Cape Dorset is consistently lower than at Iqaluit. As seen in the surface pressure evolution, at both locations the primary prevailing wind directions are clearly related to weakening or retreating cyclones (strengthening or approaching anticyclones), whereas the secondary prevailing wind directions are associated with deepening or approaching cyclones (weakening or retreating anticyclones). Consequently, extended periods of secondary prevailing wind directions, frequently occurring ahead of the warm front of approaching cyclones, are associated with warmer temperatures than extended periods of primary prevailing wind directions, frequently occurring behind the cold front of retreating cyclones.

\section{Stably stratified orographic boundary-layer flow}

On horizontal scales over which the curvature of the earth's surface can be neglected, the evolution of the atmospheric velocity field $\boldsymbol{v}=(u, v, w)^{T}$ in a rotating tangent Cartesian frame of reference centred at latitude $\phi_{\text {ref }}$ is described by

$$
\frac{\partial \boldsymbol{v}}{\partial t}+(\boldsymbol{v} \cdot \nabla) \boldsymbol{v}+2 \boldsymbol{\Omega} \times \boldsymbol{v}=-\rho^{-1} \nabla p+\boldsymbol{g}+\boldsymbol{f},
$$

where $p$ denotes pressure and $\rho$ is density. Gravitational acceleration is represented by $g=(0,0,-g)^{T}$ with 
$g=9.81 \mathrm{~m} \mathrm{~s}^{-2}$, and internal viscous forces and surface drag are denoted by $\boldsymbol{f}=\left(f_{1}, f_{2}, f_{3}\right)^{T}$. Furthermore, $\boldsymbol{\Omega}=\Omega\left(0, \cos \phi_{\text {ref }}, \sin \phi_{\text {ref }}\right)^{T}$ with $\Omega=7.292 \times 10^{-5} \mathrm{rad} \mathrm{s}^{-1}$. In these equations, all variables are assumed to be representative of motion on the shortest time-scale relevant for the problem under consideration.

For flow within an orographic channel, significant horizontal turbulent momentum fluxes between the interior and the lateral boundaries occur, as well as vertical turbulent momentum fluxes between the surface and the overlying flow. Temporal variability of the orographic boundary-layer flow due to small-scale turbulent eddies is fast compared with variations in response to large-scale weather systems or thermally generated pressure gradients within the channel, occurring over periods of a few hours to days. Given hourly surface data, as in the present case, these important turbulent velocity fluctuations are unobserved. Their effects on the slowly evolving flow component must therefore be described in parameterised form.

However, even on an hourly time-scale complex velocity fluctuations may occur that are hard to model and to predict in detail. The interest here is in the locally prevailing surface wind condition as a function of the larger-scale atmospheric circulation, represented locally by the surface geostrophic wind. As mentioned already in the introduction, the purpose of this study is to determine to what extent the climatologically prevailing wind conditions can be interpreted as attracting states of the actual flow. Then, instead of modelling the highly variable surface winds directly, the approach here is to describe the evolution of the prevailing wind conditions as a function of the larger-scale atmospheric circulation, and to determine the transition of actual surface winds to these slowly evolving climatological states of motion. For simplicity, the idealised velocity field representing the underlying stable state of the turbulent flow will be referred to as attracting flow. As shown below, the actual flow has a tendency to approach the momentarily stable climatological state, while the attracting flow itself slowly varies on the time-scale of the larger-scale atmospheric circulation.

To derive equations of motion valid for climatological flow conditions, following a common procedure in turbulence studies (Monin and Yaglom, 1971), the three-dimensional velocity field $\boldsymbol{v}$ is written here as the sum of the slowly evolving attracting flow $\overline{\boldsymbol{v}}$ and partly unobserved temporal perturbations $\boldsymbol{v}^{\prime}=\boldsymbol{v}-\overline{\boldsymbol{v}}$ therefrom. The other variables are decomposed in a similar fashion. Variables of the attracting flow are formally defined as ensemble means, involving all timeseries corresponding to a particular type of evolution. In the present case, the emphasis is on extended periods of channelled flow, such as discussed in the previous section, as well as wind shifts between channelled flow conditions, discussed in later sections.

The ensemble-averaged horizontal components of the equation of motion (1) are then given by (a)

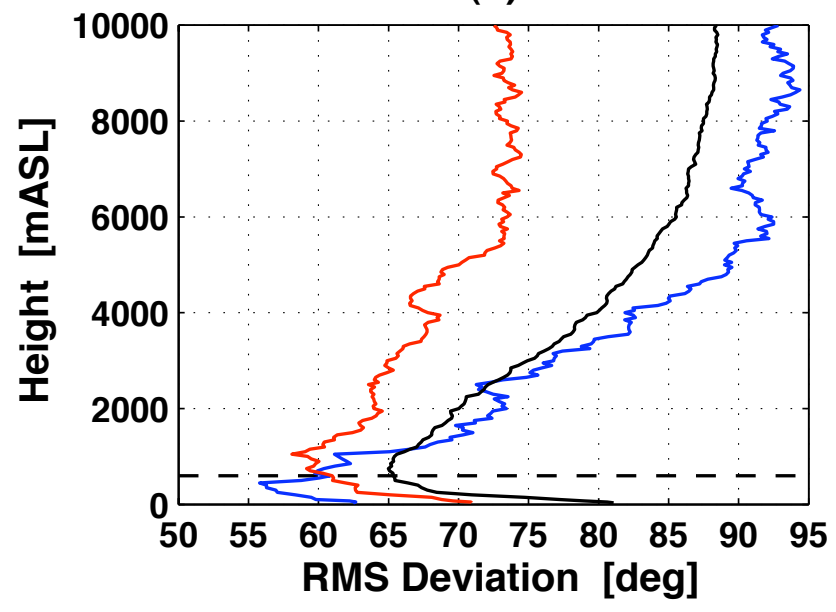

(b)

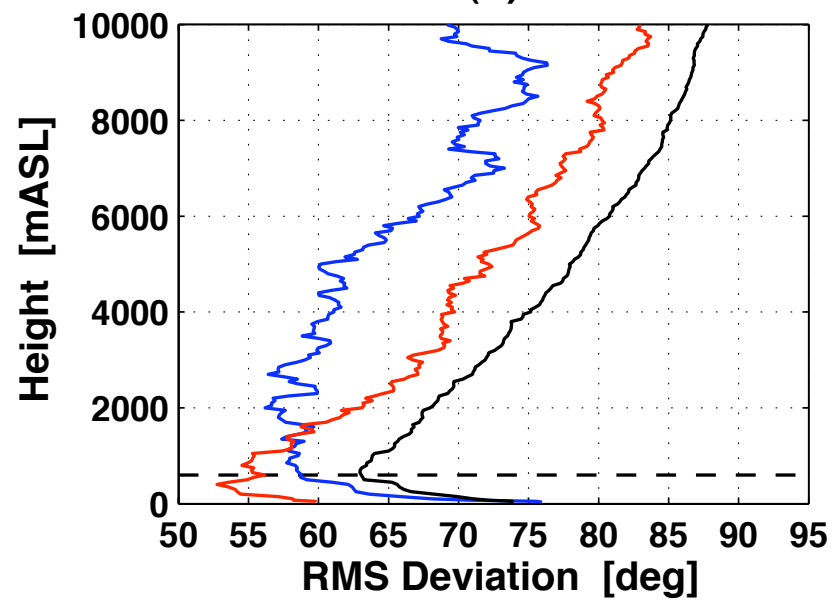

Fig. 5. Vertical profiles of root-mean-squared (RMS) differences between surface geostrophic and actual wind direction at each level in (a) winter (Jan-March), and (b) summer (July-Sep), for soundings corresponding to southeasterly (blue), northwesterly (red), and all (black) surface wind directions at Iqaluit. Ridge-top level at $600 \mathrm{mASL}$ is indicated by the dashed line.

$$
\begin{aligned}
& \frac{\partial \overline{\boldsymbol{u}}}{\partial t}+(\overline{\boldsymbol{v}} \cdot \nabla) \overline{\boldsymbol{u}}+\overline{\left(\boldsymbol{v}^{\prime} \cdot \nabla\right) \boldsymbol{u}^{\prime}}+ f \boldsymbol{k} \times \overline{\boldsymbol{u}}= \\
&-\bar{\rho}^{-1} \nabla_{z} \bar{p}+\overline{\boldsymbol{f}_{z}},
\end{aligned}
$$

where $\quad \boldsymbol{u}=(u, v, 0)^{T}, \quad \boldsymbol{k}=(0,0,1)^{T}, \quad f=2 \Omega \sin \phi_{\text {ref }}$, $\nabla_{z} p=\left(\partial_{x} p, \partial_{y} p, 0\right)^{T}, \quad f_{z}=\left(f_{1}, f_{2}, 0\right)^{T}, \quad$ and ensemble averages are represented by bars over the respective variables. In deriving this equation it was assumed that within a gently sloping valley or over water the ensemble mean vertical motion vanishes $(\bar{w}=0)$, and that fluctuations of density from the ensemble mean can be neglected in the horizontal force balance $(\rho=\bar{\rho})$. Since in this study the focus is on the climatological evolution of surface winds, to simplify the notation, bars over single ensemble-averaged variables from now on will be omitted. 
(a)

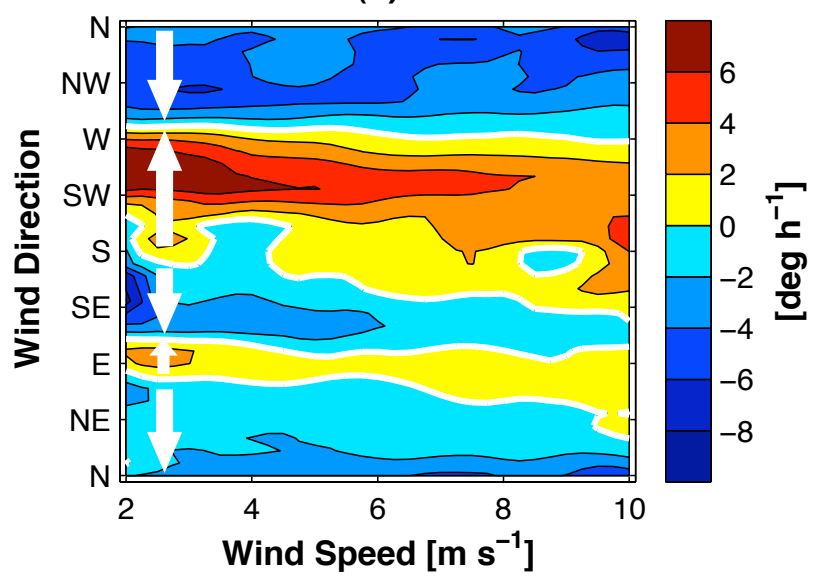

(b)

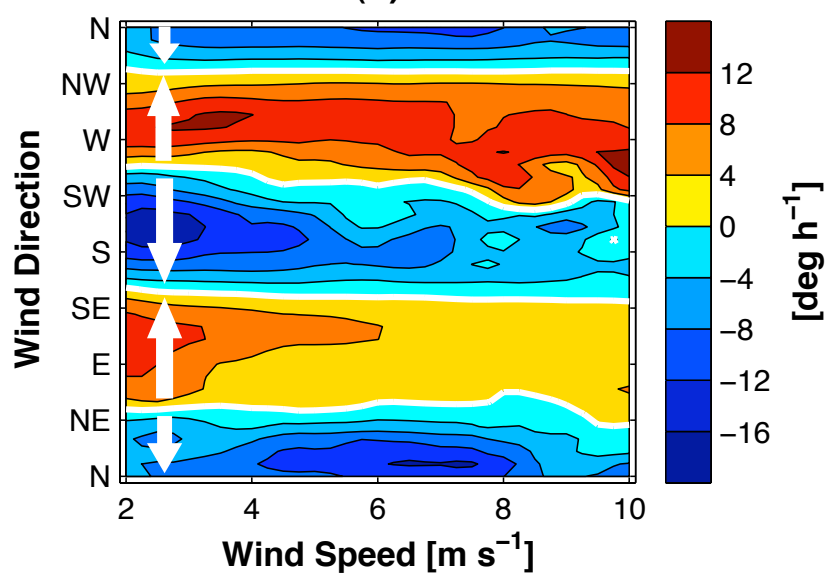

Fig. 6. Local mean hourly tendencies of surface wind direction as a function of surface wind speed and direction at (a) Cape Dorset, and (b) Iqaluit. The white zero-isoline represents statistically stationary wind directions for given wind speeds. Arrows indicate the prevailing turning of the surface wind within a given sector of wind directions.

As seen in the previous section, significant variations in wind speed typically occur during periods of stationary wind directions. The analysis of the stability of prevailing wind directions, and sudden shifts between them, therefore requires separate dynamical equations for wind speed and direction.

If, looking downward, wind direction (in radians) is measured positive clockwise from the positive y-axis to the direction from which the wind is blowing, horizontal velocity can be written as $\boldsymbol{u}=-s(\sin \phi, \cos \phi, 0)^{T}$, with horizontal wind speed $s=|\boldsymbol{u}|$. It then follows that the horizontal Lagrangian acceleration of fluid elements along their trajectories can be decomposed into components parallel and perpendicular to the (non-vanishing) horizontal velocity vector such that

$$
\begin{aligned}
\frac{d \boldsymbol{u}}{d t} & =\partial_{t} \boldsymbol{u}+(\boldsymbol{v} \cdot \nabla) \boldsymbol{u} \\
& =-a_{1} \boldsymbol{k} \times \boldsymbol{u}+a_{2} \boldsymbol{u},
\end{aligned}
$$

where

$$
\begin{aligned}
& a_{1}=d_{t} \phi=-s^{-2}(\boldsymbol{k} \times \boldsymbol{u}) \cdot \frac{d \boldsymbol{u}}{d t} \\
& a_{2}=d_{t} \ln s=s^{-2} \boldsymbol{u} \cdot \frac{d \boldsymbol{u}}{d t} .
\end{aligned}
$$

Forcing parameter $a_{1}$ therefore represents directional changes in the motion of fluid elements, and $a_{2}$ represents changes in their speed.

Above the boundary-layer, surface drag and turbulent momentum fluxes due to velocity fluctuations from the ensemble mean, represented by $-\overline{\left(\boldsymbol{v}^{\prime} \cdot \nabla\right) \boldsymbol{u}^{\prime}}$, by definition are small. In the free atmosphere, the time-rate of change of horizontal velocity is then approximately given by

$\frac{d \boldsymbol{u}}{d t}+f \boldsymbol{k} \times \boldsymbol{u}=-\rho^{-1} \nabla_{z} p$.

On horizontal isobaric surfaces, $d_{t} \boldsymbol{u}+f \boldsymbol{k} \times \boldsymbol{u}=\mathbf{0}$, and fluid elements are unaccelerated in an inertial frame of reference. It then follows from (3) that $a_{1}=-f$ and $a_{2}=0$. Consequently, as seen from (4) and (5), the flow is in anticyclonic circulatory motion at a constant speed (inertial oscillations). If the flow is unaccelerated in the rotating frame of reference such that $d_{t} \boldsymbol{u}=\mathbf{0}$, expansion coefficients $a_{1}$ and $a_{2}$, as a result of the decomposition (3), must vanish independently and fluid elements, in the rotating coordinate system, follow straightline trajectories at a constant speed. Then (6) is solved by the geostrophic velocity field

$\boldsymbol{v}_{g}=(f \rho)^{-1} \boldsymbol{k} \times \nabla_{z} p$,

where, analogous to horizontal velocity, $\boldsymbol{v}_{g}=\left(u_{g}, v_{g}, 0\right)^{T}=-$ $s_{g}\left(\sin \phi_{g}, \cos \phi_{g}, 0\right)^{T}$, with geostrophic wind speed $s_{g}=\left|\boldsymbol{v}_{g}\right|$. Validity of the geostrophic approximation requires that the acceleration of fluid elements along their trajectories is negligible and that the curvature of trajectories is weak. In the free atmosphere, to some extent this is justified for velocity fields representative of the motion around large-scale weather systems.

However, the geostrophic wind relationship (7) and more generally the large-scale force balance (6) break down under channelled flow conditions, such as the prevailing winds at Cape Dorset and Iqaluit, under which $\boldsymbol{u} \approx(\boldsymbol{c} \cdot \boldsymbol{u}) \boldsymbol{c}$, where unit vector $c=-\left(\sin \phi_{c}, \cos \phi_{c}, 0\right)^{T}$ is oriented along the local orientation of the channel axis, and $\phi_{c}$ is the most dominant along-channel wind direction $\left(\phi_{c}=3 \pi / 2\right.$ at Cape Dorset, and $\phi_{c}=7 \pi / 4$ at Iqaluit). This disruption of the large-scale force balance is caused by terrain-induced pressure gradients.

The total horizontal pressure gradient within the orographic boundary-layer, $\nabla_{z} p=\nabla_{z} p_{\mathrm{FA}}+\nabla_{z} p_{\mathrm{BL}}$, can be decomposed into a component in the overlying free atmosphere, associated with a large-scale geostrophic wind $\boldsymbol{v}_{g}$ through (7), and a boundary-layer component due to perturbation pressure $p_{\mathrm{BL}}=p_{\mathrm{thm}}+p_{\mathrm{dyn}}$, in general resulting from thermal and dynamical effects. The horizontal pressure gradient force within the orographic boundary-layer can then be written as

$-\rho^{-1} \nabla_{z} p=f \boldsymbol{k} \times \boldsymbol{v}_{g}-\rho^{-1} \nabla_{z} p_{\mathrm{BL}}$. 
(a)

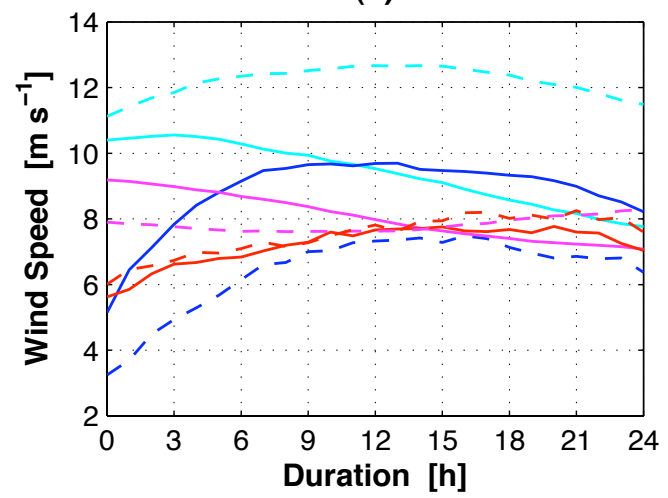

(c)

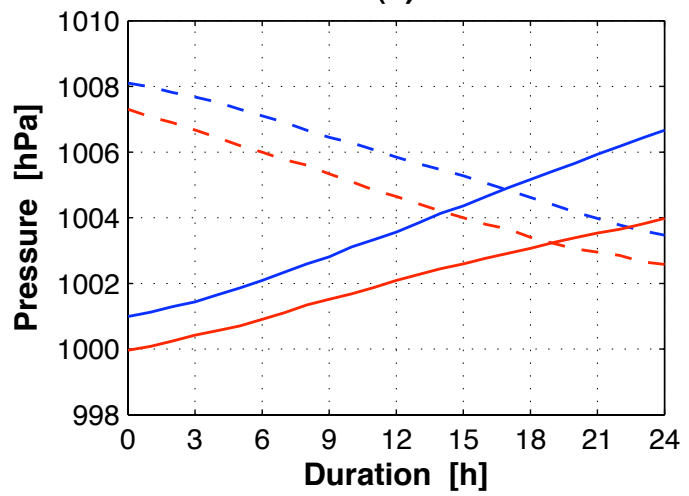

(b)

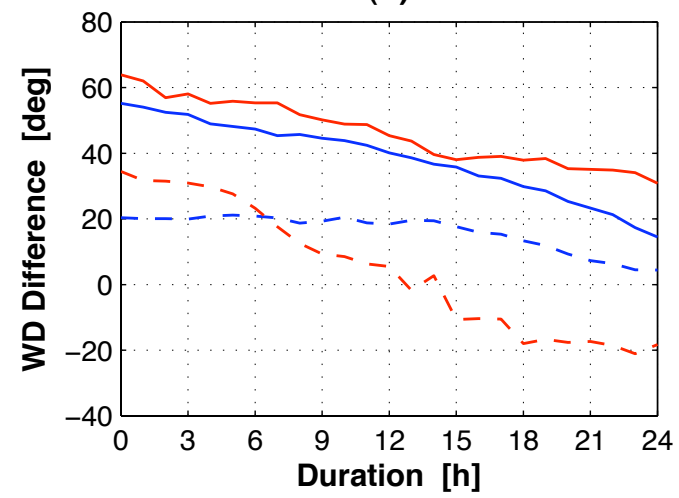

(d)

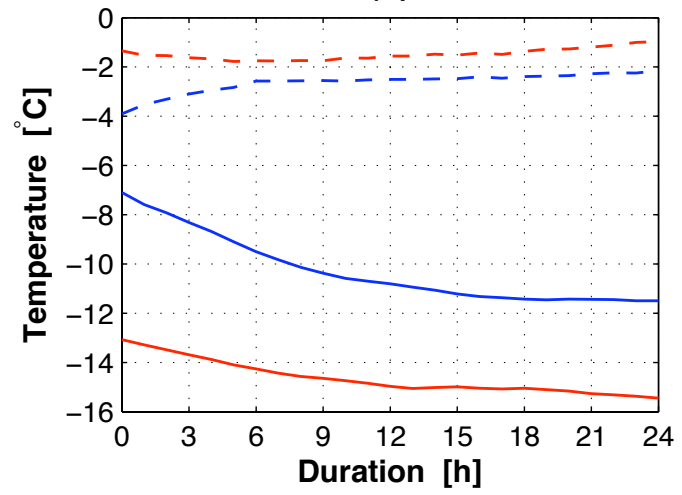

Fig. 7. Ensemble mean evolution of surface variables at Cape Dorset (red lines) and Iqaluit (blue lines) during 24-h periods of continuous primary (solid lines) and secondary (dashed lines) prevailing wind directions. In (a) also shown is the evolution of surface geostrophic wind speed at Cape Dorset (magenta lines) and Iqaluit (cyan lines) during 24-h periods of primary (solid lines) and secondary (dashed lines) prevailing wind directions. Wind direction (WD) differences are defined in Sect. 3.

To investigate the dynamics of channelled flow affected by two approximately parallel orographic barriers, it is assumed that internal perturbation pressure is mainly resulting from dynamically induced stagnation pressure at the lateral boundaries. It is therefore mainly acting in cross-channel direction,

$-\rho^{-1} \nabla_{z} p_{\mathrm{BL}} \approx-\rho^{-1}\left(\boldsymbol{n} \cdot \nabla_{z} p_{\mathrm{dyn}}\right) \boldsymbol{n}$,

where $\boldsymbol{n}=\boldsymbol{k} \times \boldsymbol{c}$. This assumption is justified for predominantly large-scale driven channelled flow, but excludes the study of thermally driven anabatic and katabatic winds within sloping valleys, or land-sea breezes at the head of fjords.

Before proceeding with the main derivation, it is interesting to note that the climatological properties of shortterm fluctuations of wind directions about the two prevailing along-channel directions, as shown in Fig. 6, can be described by a simple parameterisation of cross-channel pressure gradients. This is achieved by assuming that the internal stagnation pressure distribution close to the lateral boundaries is given by

$\left.\rho^{-1} \nabla_{z} p_{\mathrm{dyn}}\right|_{\text {lat }}=c(\boldsymbol{n} \cdot \boldsymbol{u}) \boldsymbol{n}$, where $c$ can be any positive definite real function of wind speed. To make dynamic pressure vary with the square of wind speed, let $c \sim s$. However, the dynamical results derived from this expression of stagnation pressure gradients are not sensitive to the exact parameterisation chosen. Then, with Lagrangian acceleration $d_{t} \boldsymbol{u}=-c(\boldsymbol{n} \cdot \boldsymbol{u}) \boldsymbol{n}$ it follows from (3), (4), and (5) that the total time derivatives of wind direction and speed due to stagnation pressure gradients close to the lateral boundaries are given by

$$
\begin{aligned}
(\dot{\phi})_{\text {stag }} & =-c \sin \phi \cos \phi \\
(\dot{s})_{\text {stag }} & =-c s \sin ^{2} \phi,
\end{aligned}
$$

where here and in the following the substitutions $\left(\phi-\phi_{c}\right) \rightarrow$ $\phi$, and $\left(\phi_{g}-\phi_{c}\right) \rightarrow \phi_{g}$ have been made. Actual and geostrophic wind directions are therefore measured relative to the most frequent along-channel wind direction $\phi_{c}$. As seen from (11), independent of wind speed, along-channel wind directions $\phi=\{0, \pi\}$ and cross-channel wind directions $\phi=\{\pi / 2,3 \pi / 2\}$ are steady. With $\partial_{\phi}(\dot{\phi})_{\text {stag }}=c\left(\sin ^{2} \phi-\cos ^{2} \phi\right)$ it follows that $\partial_{\phi}(\dot{\phi})_{\text {stag }}=-c<0$ for along-channel winds, and $\partial_{\phi}(\dot{\phi})_{\text {stag }}=c>0$ for cross-channel winds. Along-channel 


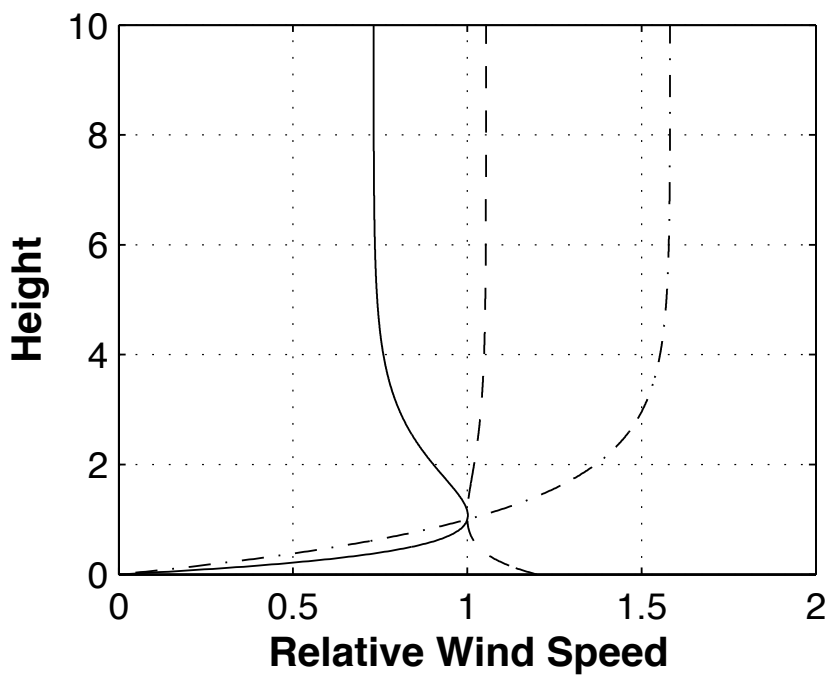

Fig. 8. Wind speed in units of the speed at ridge-top level versus height in units of ridge-top level, calculated with (21) and (22) for different parameter values: $\delta_{1}=1, \varepsilon=0$, and zero surface speed (dash-dotted line); $\delta_{1}=2, \delta_{2}=1, \varepsilon=0.5$, and a surface speed of 1.2 in the same direction as the ridge-top level flow (dashed line); $\delta_{1}=2$, $\delta_{2}=1, \varepsilon=0.5$, and zero surface speed (solid line).

wind directions are therefore stable equilibria, whereas cross-channel wind directions are unstable. This is consistent with the average wind direction tendencies shown in Fig. 6, indicating that, for the most part, on an hourly basis, winds at Cape Dorset and Iqaluit fluctuate around their prevailing directions due to stabilising effects of terrain-induced stagnation pressure gradients at the lateral boundaries. However, these channelling effects do not explain shifts between the two prevailing wind directions. It can also be seen from (12) that stagnation pressure gradients are dissipative, decelerating winds with cross-channel flow components. They can therefore not be responsible for the acceleration that typically occurs during extended periods of channelled winds as seen in Fig. 7. Although their stabilising effect is important, stagnation pressure gradients as parameterised by (10) cannot be the main forcing mechanism for along-channel winds.

More generally, under channelled flow conditions with $\boldsymbol{u} \approx(\boldsymbol{c} \cdot \boldsymbol{u}) \boldsymbol{c}$, it follows from (2) that

$$
\begin{aligned}
\boldsymbol{c} \cdot \frac{d \boldsymbol{u}}{d t}= & -\boldsymbol{c} \cdot\left(\overline{\left(\boldsymbol{v}^{\prime} \cdot \nabla\right) \boldsymbol{u}^{\prime}}\right)-\rho^{-1} \boldsymbol{c} \cdot \nabla p+\boldsymbol{c} \cdot \boldsymbol{f} \\
\boldsymbol{n} \cdot \frac{d \boldsymbol{u}}{d t}= & -\boldsymbol{n} \cdot\left(\overline{\left(\boldsymbol{v}^{\prime} \cdot \nabla\right) \boldsymbol{u}^{\prime}}\right)-f \boldsymbol{c} \cdot \boldsymbol{u} \\
& -\rho^{-1} \boldsymbol{n} \cdot \nabla p+\boldsymbol{n} \cdot \boldsymbol{f}
\end{aligned}
$$

For persistent channelled flows to establish, the total crossbarrier acceleration along trajectories (14) must vanish. This leads to the approximate balance equation

$f s_{c}=-\rho^{-1} \boldsymbol{n} \cdot \nabla p-\boldsymbol{n} \cdot\left(\overline{\left(\boldsymbol{v}^{\prime} \cdot \nabla\right) \boldsymbol{u}^{\prime}}\right)+\boldsymbol{n} \cdot \boldsymbol{f}$ where $s_{c}=\boldsymbol{c} \cdot \boldsymbol{u}$ is the along-channel wind component. Channelling therefore requires the establishment of a stable balance in cross-channel direction between Coriolis force, horizontal pressure gradients, lateral as well as bottom surface drag, and turbulent momentum transfer. To a large extent, the relative magnitudes of these terms depend on the width and depth of the channel. In a narrow channel, larger horizontal momentum transfer must be expected for a given alongchannel wind speed than in a wide channel. This must then be balanced by stronger dynamic pressure gradients due to more intense cross-channel velocity perturbations at the lateral boundaries. Similarly, for a given intensity of the overlying flow, downward momentum transfer at the bottom of a shallow channel must be expected to be larger than in a deep channel. Towards the top of the terrain, cross-channel turbulent momentum transfer and surface drag become less important, and balance Equation (15) approaches the crosschannel component of the geostrophic wind relationship (7) between Coriolis force and large-scale pressure gradients.

\section{Local models of channelled boundary-layer flow}

At many communities in the Arctic, including Cape Dorset, only hourly surface data are available on a regular basis. To be able to apply (2) to the study of low-level winds at these isolated locations, the terms describing surface drag and turbulent momentum transfer must be parameterised using local surface variables only.

As seen in the following sections in comparison with the long-term data record, for attracting flow describing climatological surface wind conditions within high-latitude orographic channels, the net effects of internal viscous forces and surface drag can be described by a simple Rayleigh drag parameterisation,

$\boldsymbol{f}=-\boldsymbol{r}^{\prime} \boldsymbol{u}$

normally valid only for a highly viscous fluid. This simple parameterisation is therefore the dynamical representation of the statistical fact that unsystematic turbulent fluctuations are removed by the ensemble averaging.

To simplify the expression of turbulent transfer of horizontal momentum, it is separated into horizontal and vertical components,

$\overline{\left(\boldsymbol{v}^{\prime} \cdot \nabla\right) \boldsymbol{u}^{\prime}}=\overline{\left(\boldsymbol{u}^{\prime} \cdot \nabla\right) \boldsymbol{u}^{\prime}}+\overline{w^{\prime} \partial_{z} \boldsymbol{u}^{\prime}}$.

For simplicity it is assumed here that significant horizontal turbulent momentum transfer only occurs between the side walls and the channel interior. Horizontal momentum transfer is then mainly acting in cross-channel direction and can be approximated by

$\overline{\left(u^{\prime} \cdot \nabla\right) u^{\prime}} \approx n \cdot\left(\overline{\left(u^{\prime} \cdot \nabla\right) u^{\prime}}\right) n$.

Since the side walls are rigid, horizontal momentum fluxes are always dissipative. 
Contrary to this, downward momentum transfer from the overlying flow may be the main forcing mechanism for flow over complex terrain, particularly between two orographic barriers. Given only surface data at one location, there is no way of distinguishing different modes of momentum transfer to lower levels. In addition to turbulent fluctuations on various scales, significant transfer may also occur due to orographic waves or secondary circulations within the channel. For simplicity, the combined effects of these mechanisms will be referred to as turbulent momentum transfer. They can jointly be parameterised based on Prandtl's mixing length hypothesis, in which it is assumed that turbulent perturbations in horizontal velocity are mainly due to the advection $-w^{\prime} \partial \boldsymbol{u} / \partial z$ of ensemble-averaged horizontal momentum by perturbation vertical velocity. This results in horizontal velocity perturbations

$\boldsymbol{u}^{\prime}=-\xi \frac{\partial \boldsymbol{u}}{\partial z}$,

where the vertical eddy displacement length $\xi$ depends on the typical intensity, size, and lifetime of dominant turbulent eddies. It therefore depends on the static stability of the boundary-layer stratification, and is likely to show large temporal and spatial variability. Vertical momentum transfer is then given by

$$
-\overline{w^{\prime} \frac{\partial \boldsymbol{u}^{\prime}}{\partial z}}=\overline{w^{\prime} \frac{\partial \xi}{\partial z}} \frac{\partial \boldsymbol{u}}{\partial z}+\overline{w^{\prime} \xi} \frac{\partial^{2} \boldsymbol{u}}{\partial z^{2}} .
$$

To obtain a simple parameterisation of turbulent momentum transfer, it is assumed that the vertical dependence of ensemble-averaged horizontal velocity at any height $z^{\prime} \leq D$ at or below ridge-top level $D$ can be described by

$\boldsymbol{u}\left(z^{\prime}\right)=\boldsymbol{a}_{0} S\left(z^{\prime}\right)+\boldsymbol{u}_{0}$,

where $\boldsymbol{u}_{0}=\boldsymbol{u}\left(z_{0}\right)$ at level $z_{0}$ at which analytic shear function $S$ is equal to zero. Then, with velocity data at any other reference level $z \neq z_{0}, \boldsymbol{a}_{0}=\left(\boldsymbol{u}(z)-\boldsymbol{u}_{0}\right) / S(z)$.

For the logarithmic wind profile often assumed in the neutrally stratified boundary-layer, $S\left(z^{\prime}\right)=\log \left(z^{\prime} / D\right)$ for $z^{\prime}>0$. Then $S(D)=0$, and $\boldsymbol{u}_{0}=\boldsymbol{u}(D) \approx \boldsymbol{v}_{g}(D)=\boldsymbol{v}_{g}\left(z^{\prime}\right)$, where, as discussed in Sect. 3, it was assumed that the flow at ridgetop level is approximately geostrophic. However, low-level speed maxima are a common occurrence within the stable high-latitude boundary-layer (e.g., Brümmer and Thiemann, 2002; Brümmer et al., 2005; Nawri and Stewart, 2006). In these cases, a logarithmic wind profile is not a valid representation of the low-level shear. A more general description of the vertical dependence of ensemble-averaged horizontal velocity, including also the presence of low-level speed maxima, is given by the shear profile

$S\left(z^{\prime}\right)=\frac{e^{\frac{\delta_{1}\left(D-z^{\prime}\right)}{D}}-1}{e^{\delta_{1}}-1}-\varepsilon \frac{e^{\frac{\delta_{2}\left(D-z^{\prime}\right)}{D}}-1}{e^{\delta_{2}}-1}$,

where $\delta_{1,2}$ and $\varepsilon$ are positive constants. As for the logarithmic wind profile, $S(D)=0$, and $\boldsymbol{u}_{0}=\boldsymbol{v}_{g}$. Vertical profiles of

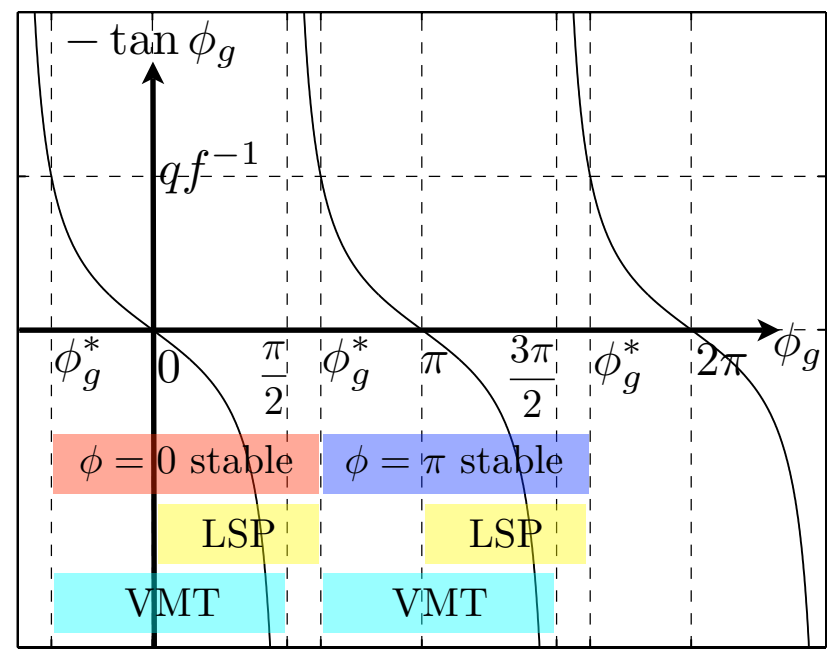

Fig. 9. Schematic representation of the range of stability of channelled surface wind directions over surface geostrophic wind direction as a function of the vertical momentum transfer coefficient $q$. Also indicated are the ranges of positive contribution to the acceleration of channelled surface winds from large-scale pressure gradients (LSP) and vertical momentum transfer (VMT).

wind speed calculated with (21) and (22) are shown in Fig. 8 for different parameter values. For $\delta_{1}=1, \varepsilon=0$, and zero surface speed a logarithmic-like wind speed profile is obtained which increases rapidly close to the surface and more slowly aloft. For $\delta_{1}=2, \delta_{2}=1, \varepsilon=0.5$, and a surface wind in the same direction as the ridge-top level flow, the vertical wind speed profile is similar to those typically found at Iqaluit under strong northwesterly surface wind conditions in winter, with higher near-surface wind speeds than at ridge-top level (Nawri and Stewart, 2006). Again for $\delta_{1}=2, \delta_{2}=1, \varepsilon=0.5$, but with zero surface speed, a vertical wind speed profile is found similar to those at Iqaluit under strong southeasterly surface wind conditions in summer, with the highest wind speeds at ridge-top level (Nawri and Stewart, 2006).

Generally, from (20) and (21) it follows that at any reference height $z \leq D$

$-\overline{w^{\prime} \partial_{z} \boldsymbol{u}^{\prime}}=q\left(\boldsymbol{v}_{g}-\boldsymbol{u}\right)$,

with vertical momentum transfer coefficient

$q=-\frac{1}{S(z)}\left(\left.\overline{w^{\prime} \frac{\partial \xi}{\partial z^{\prime}}} \frac{\partial S}{\partial z^{\prime}}\right|_{z^{\prime}=z}+\left.\overline{w^{\prime} \xi} \frac{\partial^{2} S}{\partial z^{\prime 2}}\right|_{z^{\prime}=z}\right)$

which, at a given location and for a particular climatological flow situation, must be determined from observations. In the following section, this will be done based on an analysis of the stability of prevailing wind directions. It is shown that the same value for $q$ is obtained not only for different channelled wind conditions at each location, but also for the two locations considered in this study. 
(a)

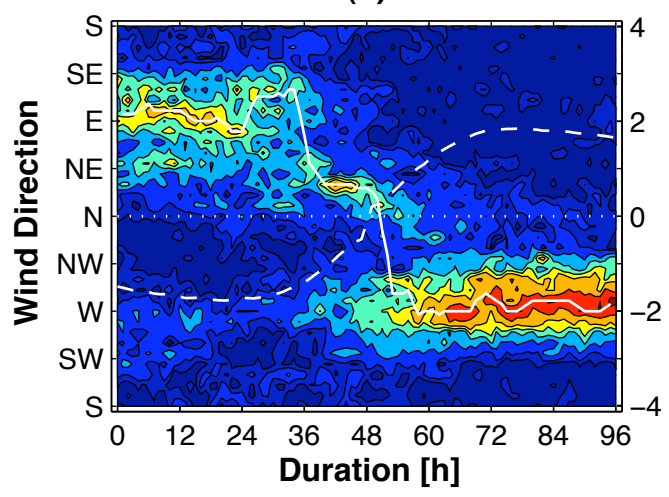

(c)

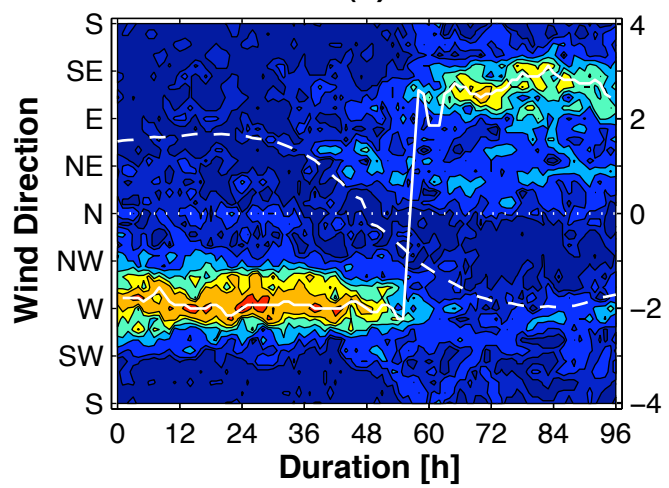

(b)

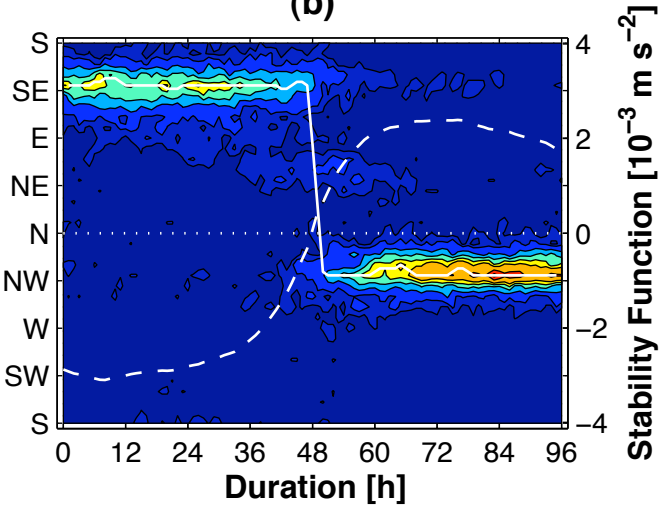

(d)

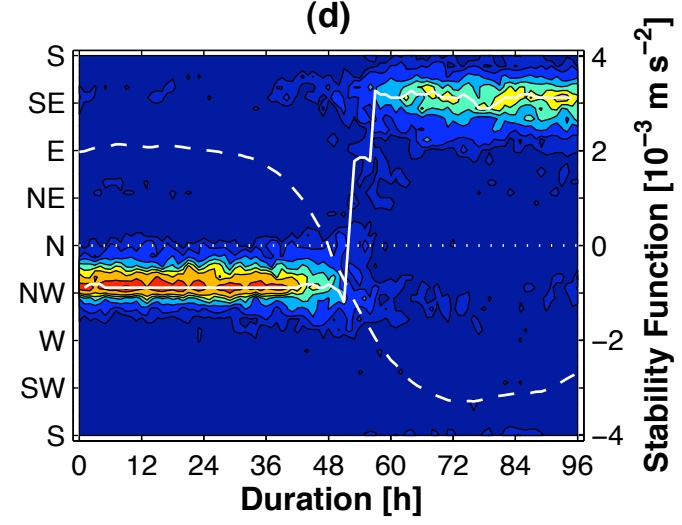

Fig. 10. Evolution of surface wind directions at Cape Dorset ((a) and (c)) and Iqaluit ((b) and (d)), following transitions across zero of stability function $\sigma$. Stability is negative (positive) in the first (second) half of the period in (a) and (b), and vice versa in (c) and (d). Colour shading of normalised occurrence is the same as in Fig. 3. The solid white line connects the most frequent wind directions at each hour. The ensemble mean stability function is represented by the dashed white line.

Then, substituting (9), (16), (17), (18), and (23) into (13), the along-channel component of the horizontal equations of motion for channelled flow is approximately given by

$\frac{d \boldsymbol{u}}{d t}=\boldsymbol{v}_{g} \cdot(q \boldsymbol{c}-f \boldsymbol{n}) \boldsymbol{c}-r \boldsymbol{u}$,

where $r=q+r^{\prime}$. Under the assumptions made, channelled flow is therefore mainly affected by the along-barrier components of large-scale pressure gradients and vertical turbulent momentum transfer, and damped by surface drag.

\section{Prevailing wind directions}

Before analysing the combined effects on channelled flow of along-channel large-scale pressure gradients and vertical momentum transfer, it is instructive to study their isolated effects.

\subsection{Large-scale pressure gradients}

Similar to the discussion of stagnation pressure gradients in the previous section, with Lagrangian acceleration $d_{t} \boldsymbol{u}=-f\left(\boldsymbol{n} \cdot \boldsymbol{v}_{g}\right) \boldsymbol{c}$ due to along-channel large-scale pressure gradients, it follows that

$$
\begin{aligned}
(\dot{\phi})_{\mathrm{LSP}} & =-f \mu^{-1} \sin \phi_{g} \sin \phi \\
(\dot{s})_{\mathrm{LSP}} & =f s_{g} \sin \phi_{g} \cos \phi,
\end{aligned}
$$

where $\mu=s_{g}^{-1} s$. Independent of wind speed and large-scale pressure gradients, along-channel wind directions $\phi=\{0, \pi\}$ are steady. With $\partial_{\phi}(\dot{\phi})_{\mathrm{LSP}}=-f \mu^{-1} \sin \phi_{g} \cos \phi$ it follows that, in the northern hemisphere, $\phi=0$ is a stable equilibrium for $0<\phi_{g}<\pi$, whereas $\phi=\pi$ is a stable equilibrium for $\pi<\phi_{g}<2 \pi$. In both cases channelled winds are stable if the surface geostrophic wind is veered relative to the actual surface wind. Based on along-channel large-scale pressure gradients, transitions between the two prevailing channelled wind directions therefore occur with along-channel geostrophic wind directions. This situation was referred to as pressure driven channelling by Whiteman and Doran (1993). Since $(\dot{s})_{\mathrm{LSP}}=-s \partial_{\phi}(\dot{\phi})_{\mathrm{LSP}}$, local and downstream acceleration of channelled flow along trajectories occurs under conditions of stable stationary wind direction, i.e., if $\boldsymbol{u}$ is directed towards lower pressure. This is consistent with the initial increase in wind speed under stationary along-channel wind directions at Cape Dorset and Iqaluit shown in Fig. 7. 
Additionally there are temporary stationary wind directions with cross-channel components for vanishing largescale pressure gradients, $s_{g}=0$, as well as for along-channel geostrophic wind directions $\phi_{g}=\{0, \pi\}$. However, since under these conditions $\partial_{\phi}(\dot{\phi})_{\mathrm{LSP}}=0$, neither along- nor crosschannel winds are stable equilibria.

\subsection{Vertical momentum transfer}

Similarly, with Lagrangian acceleration $d_{t} \boldsymbol{u}=q\left(\boldsymbol{c} \cdot \boldsymbol{v}_{g}\right) \boldsymbol{c}-r \boldsymbol{u}$ due to along-channel vertical momentum transfer and surface drag, it follows that

$$
\begin{aligned}
(\dot{\phi})_{\mathrm{VMT}} & =-q \mu^{-1} \cos \phi_{g} \sin \phi \\
(\dot{s})_{\mathrm{VMT}} & =q s_{g} \cos \phi_{g} \cos \phi-r s .
\end{aligned}
$$

As for the forcing by along-channel large-scale pressure gradients, independent of wind speed and large-scale pressure gradients, along-channel wind directions $\phi=\{0, \pi\}$ are steady. With $\partial_{\phi}(\dot{\phi})_{\mathrm{VMT}}=-q \mu^{-1} \cos \phi_{g} \cos \phi$ it follows that $\phi=0$ is a stable equilibrium for $-\pi / 2<\phi_{g}<\pi / 2$, whereas $\phi=\pi$ is a stable equilibrium for $\pi / 2<\phi_{g}<3 \pi / 2$. In both cases channelled winds are stable if they are pointing into the same direction as the along-channel component of the overlying flow, approximated by the surface geostrophic wind. Based on along-channel vertical momentum transfer, transitions between the two prevailing channelled wind directions therefore occur with cross-channel geostrophic wind directions. This situation was referred to as forced channelling by Whiteman and Doran (1993). Since $(\dot{s})_{\mathrm{VMT}}=-$ $s\left(\partial_{\phi}(\dot{\phi})_{\text {VMT }}+r\right)$, local and downstream deceleration of channelled flow by surface drag is reduced under conditions of stable stationary wind direction, i.e., if $\boldsymbol{u} \cdot \boldsymbol{v}_{g}>0$. With subgeostrophic surface winds there is the possibility that $-\partial_{\phi}(\dot{\phi})_{\mathrm{VMT}}>r$. Net turbulent fluxes may then also contribute to the initial increase in wind speed under stationary alongchannel wind directions at Cape Dorset and Iqaluit shown in Fig. 7.

Additionally, there are temporary stationary wind directions with cross-channel components for $s_{g}=0$, as well as for $\phi_{g}=\{\pi / 2,3 \pi / 2\}$. However, similar to the forcing by largescale pressure gradients discussed above, there are no stable wind directions under these conditions.

\subsection{Combined forcing}

The significance of the surface geostrophic wind as both a representation of large-scale pressure gradients as well as an approximation of the flow immediately above the terrain, results in a subtle balance between the effects of alongchannel large-scale pressure gradients and vertical momentum transfer on flow within an orographic channel. Strong large-scale pressure gradients as those associated with cyclonic storm systems potentially not only increase the alongchannel component of large-scale pressure gradients, but also the magnitude of the overlying flow. As mentioned above, the wind direction within the channel is determined by the along-channel component of the large-scale pressure gradient, as well as by the along-channel component of the overlying flow. This balance between two forcing mechanisms allows two regimes of channelled flow, with flow against and with the direction of the large-scale pressure gradient force. Taking into account only large-scale pressure gradients, the strongest flow would develop in a straight channel with a steady geostrophic wind perpendicular to the channel axis. On the other hand, taking into account only vertical momentum fluxes, the strongest flow would develop with a geostrophic wind along the channel axis, whereas a cross-channel geostrophic wind would cause strong turbulence within the channel and dissipation of momentum at the lateral boundaries and the bottom surface.

Quantitatively the balance between along-channel largescale pressure gradients and vertical momentum transfer, for all but calm wind conditions within the channel, is expressed by the combined system of equations

$$
\begin{aligned}
\dot{\phi} & =(\dot{\phi})_{\mathrm{LSP}}+(\dot{\phi})_{\mathrm{VMT}} \\
& =-\mu^{-1} \sin \phi\left(f \sin \phi_{g}+q \cos \phi_{g}\right) \\
\dot{s} & =(\dot{s})_{\mathrm{LSP}}+(\dot{s})_{\mathrm{VMT}} \\
& =s_{g} \cos \phi\left(f \sin \phi_{g}+q \cos \phi_{g}\right)-r s .
\end{aligned}
$$

As any forcing term parallel to $\boldsymbol{u}$, the drag term $-r \boldsymbol{u}$ in (25) has no effect on the direction of the horizontal wind. Equations (30) and (31) are a closed system for air parcel trajectories within the channel if geostrophic wind is considered to be a slowly varying external parameter. The stability of channelled wind conditions and exchanges of stability between different prevailing wind directions can therefore be investigated as a function of large-scale pressure gradients. As for the individual dynamical systems, independent of wind speed and large-scale pressure gradients, along-channel wind directions $\phi=\{0, \pi\}$ are steady. With $\partial_{\phi} \dot{\phi}=-\mu^{-1} \cos \phi\left(f \sin \phi_{g}+q \cos \phi_{g}\right)$ it is useful to define the large-scale stability function

$\sigma=s_{g}\left(f \sin \phi_{g}+q \cos \phi_{g}\right)$.

Then, the primary wind direction $\phi=0$ is stable if $\sigma>0$, and the secondary wind direction $\phi=\pi$ is stable if $\sigma<$ 0 . It therefore follows that $\phi=0$ is a stable equilibrium if $-\tan \phi_{g}<q f^{-1}$ for $-\pi / 2<\phi_{g}<\pi / 2$, and $-\tan \phi_{g}>q f^{-1}$ for $\pi / 2<\phi_{g}<3 \pi / 2$. Complementary to that, $\phi=\pi$ is a stable equilibrium if $-\tan \phi_{g}>q f^{-1}$ for $-\pi / 2<\phi_{g}<\pi / 2$, and $-\tan \phi_{g}<q f^{-1}$ for $\pi / 2<\phi_{g}<3 \pi / 2$. Additionally, $\phi=0$ $(\phi=\pi)$ is stable (unstable) for $\phi_{g}=\pi / 2$ and unstable (stable) for $\phi_{g}=3 \pi / 2$.

\section{Sudden wind shifts}

In the previous section, the prevailing wind directions in orographic channels were associated with stationary states of the 
(a)

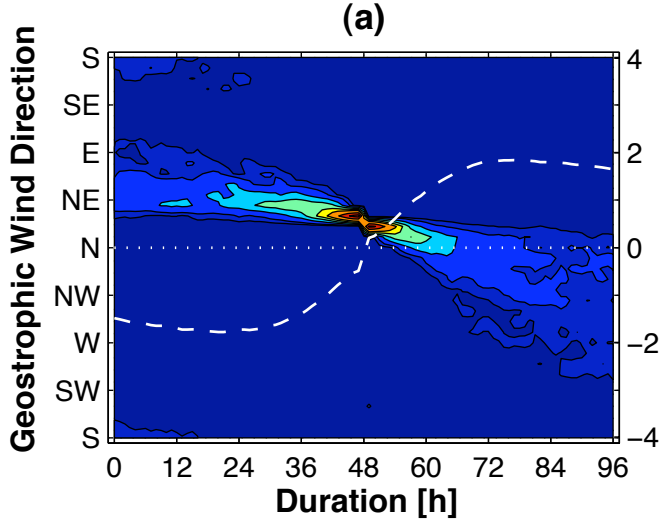

(c)

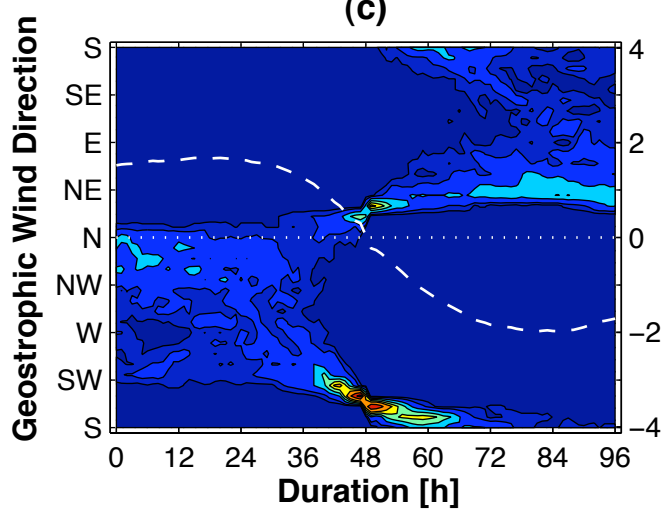

Fig. 11. As Fig. 10, for surface geostrophic wind directions.

dynamical equation (30). Consequently, shifts between the prevailing wind directions are associated with a transfer of stability between the corresponding stationary states. ${ }^{1}$

The range of stability of steady along-channel wind directions as a function of geostrophic wind direction is shown schematically in Fig. 9. As indicated, wind shifts are associated with an exchange of the active forcing mechanism (large-scale pressure gradients or vertical momentum transfer). In a comparison with Fig. 3 it can be seen that at Cape Dorset, climatologically, shifts between the two prevailing surface wind directions occur with surface geostrophic winds from north-northeast and south-southwest, or at the critical geostrophic wind directions $\phi_{g}^{*}=\{5 \pi / 8,13 \pi / 8\}$ in the rotated frame of reference introduced above. This implies that $q f^{-1}=-\tan \phi_{g}^{*}=2.41$. At Iqaluit, shifts between the two prevailing surface wind directions, climatologically, occur with surface geostrophic winds from east-northeast and west-southwest, i.e., again with $\phi_{g}^{*}=\{5 \pi / 8,13 \pi / 8\}$ and $q f^{-1}=2.41$. In both cases, wind shifts occur with geostrophic wind directions approximately perpendicular to the channel axis. This is in contrast with the cases of flow

\footnotetext{
${ }^{1}$ Since the two stationary states coexist for all parameter values, and since they are not functions of any of the system parameters, these stability transitions, in a strict sense, cannot be classified as bifurcations.
}

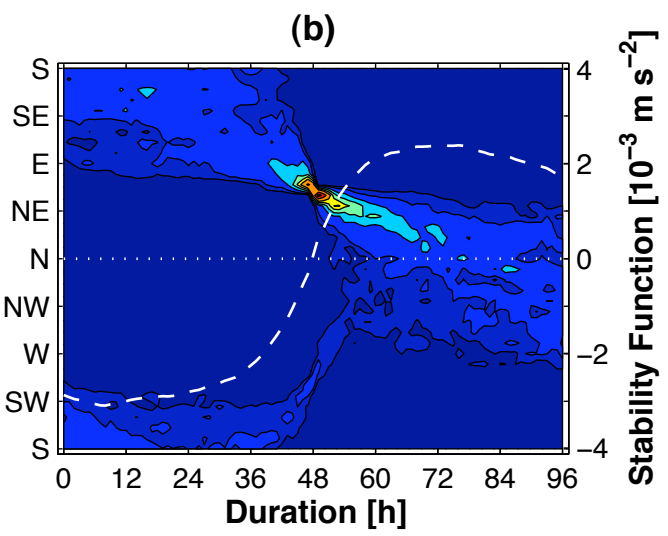

(d)

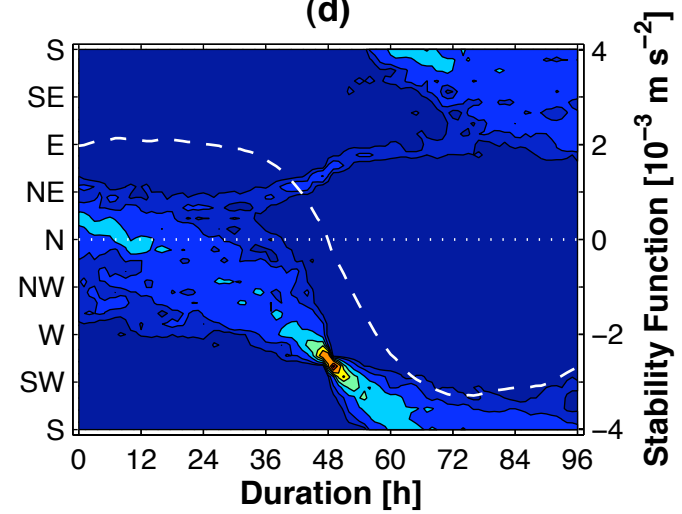

within the Rhine Valley (Gross and Wippermann, 1987) and the Tennessee Valley (Whiteman and Doran, 1993), where prevailing wind directions are determined almost exclusively by the along-valley component of large-scale pressure gradients, with transitions between prevailing channelled wind directions consequently occurring with geostrophic wind directions aligned with the channel axis. However, the critical geostrophic wind direction in a rotated frame of reference of $5 \pi / 8$, as found at Cape Dorset and Iqaluit, is very similar to those found at Payerne (Furger, 1992), and at several locations within the Baar Basin (Klaus et al., 2003). An adaptation of the simplified model to different locations therefore means, primarily, the determination of the appropriate value of

$q|f|^{-1}=\frac{\left|\overline{w^{\prime} \partial_{z} \boldsymbol{u}^{\prime}}\right|\left|\boldsymbol{v}_{g}\right|}{\left|\rho^{-1} \nabla_{z} p\right|\left|\boldsymbol{v}_{g}-\boldsymbol{u}\right|}$.

For given low-level and overlying flow conditions, this combined parameter measures the magnitude of vertical transfer of horizontal momentum relative to horizontal pressure gradients, and can therefore be interpreted as a coupling parameter between the flow within and above the valley. For $q f^{-1}=0$, on a statistical basis, surface winds are completely decoupled from the overlying flow, and only depend on pressure gradients within the valley. If these pressure gradients are primarily associated with the large-scale circulation, 
surface wind directions within the valley are such that there is net veering between the surface and ridge-top level. More detailed observational and modelling studies are required to determine to what extend sheltered valley flows fall into the two categories of the coupling parameter that have been observed so far, being either equal to 0 or 2.4, and in which way the coupling parameter depends on the exact details of valley geometry, atmospheric boundary-layer stratification, and speed and direction of the overlying flow.

An important point to consider is that although $\sigma\left(\phi_{g}^{*}\right)=0$, this does not necessarily imply that at the stability transition point the along-channel components of large-scale pressure gradients and vertical momentum transfer are small. Rather, the vanishing overall acceleration is due to a balance between two individually strong forcing terms. Transitions between prevailing wind directions are then likely to be associated with strong gusts and turbulence not necessarily seen in the hourly data values.

Since $\partial_{\phi_{g}}^{2} \sigma=-\sigma$, an extremum of $\sigma$ with respect to geostrophic wind direction must either be a global maximum or minimum. Stability and speed forcing are therefore maximised with respect to $\phi_{g}$ if $\partial_{\phi_{g}} \sigma=0$. This is satisfied for geostrophic wind directions $\widehat{\phi}_{g}$ and $\widehat{\phi}_{g}+\pi$ if $q f^{-1}=\cot \widehat{\phi}_{g}=-\tan \phi_{g}^{*}$, or if $\widehat{\phi}_{g}=\phi_{g}^{*}+\pi / 2$. Stationary along-channel wind directions are therefore maximally stable with geostrophic wind directions perpendicular to the critical directions at which wind shifts occur. At the two locations considered here, this would be the case with overlying flow approximately along the channel axis, indicating again the importance of downward momentum transfer.

The ranges of geostrophic wind directions over which large-scale pressure gradients and downward momentum transfer are positively active depend on the magnitude of the vertical momentum transfer coefficient relative to the magnitude of the Coriolis parameter. Since at Cape Dorset and Iqaluit $\left|q f^{-1}\right|>1$, the range of geostrophic wind directions of $7 \pi / 4$ over which along-channel vertical momentum transfer is positively active is larger than the range of $5 \pi / 4$ over which along-channel large-scale pressure gradients are active. This does not necessarily imply that over time alongchannel downward momentum transfer is the dominant forcing mechanism. However, at Cape Dorset, on an hourly basis, vertical momentum transfer is $10 \%(58 \%)$ more frequently accelerating than large-scale pressure gradients for the primary (secondary) wind direction. At Iqaluit, vertical momentum transfer is $31 \%$ (21\%) more frequently accelerating primary (secondary) wind directions.

To test the validity of the stability criteria discussed above, and to determine the typical response time of surface wind directions to a changing large-scale surface pressure distribution, Fig. 10 shows the hourly histogram evolution of wind directions at Cape Dorset and Iqaluit over all 4-day periods within the study period, during which stability function $\sigma$ changes sign once after $48 \mathrm{~h}$.
As seen in Sect. 3, wind direction generally is more variable at Cape Dorset than at Iqaluit, with a larger difference between the occurrence of primary and secondary wind directions. Initially prevailing easterly winds at Cape Dorset shift to occasionally strong north-northeasterly winds about $12 \mathrm{~h}$ prior to the stability transition. Wind directions during this transitorily stable state are essentially geostrophic and must be maintained against channelling effects by strong vertical momentum transfer. The subsequent shift to westerly winds typically occurs within $3 \mathrm{~h}$ after the shift in large-scale stability. In contrast, initially stable southeasterly winds at Iqaluit persist throughout the period of negative stability, followed by a rapid shift of wind direction to northwest within about $3 \mathrm{~h}$ following the stability transition. Due to the more dominant channelling effects, east-northeasterly winds at the transition point are not as common as comparable crosschannel winds at Cape Dorset. Initially stable primary wind directions at both locations rapidly shift to the secondary wind direction about 3-9 h after the stability function becomes negative.

Overall, surface winds at both locations tend to adjust to the large-scale stable direction within 3-9h. On that timescale and longer, predictions of highly ageostrophic channelled wind directions are possible based on the large-scale surface pressure distribution. If stability conditions of a particular along-channel wind direction persist for more than $9 \mathrm{~h}$, a significant increase in surface wind speed must be expected.

\section{Large-scale weather patterns}

The exact nature of shifts between prevailing wind directions and typical large-scale weather patterns associated with them can qualitatively be determined from the evolution of surface geostrophic wind directions shown in Fig. 11, for ensembles of the same 4-day periods discussed in the previous section.

Exchanges of large-scale stability from easterly to westerly wind directions over a 4-day period at Cape Dorset are most frequently associated with geostrophic winds backing from northeast to northwest. This suggests a connection with northward moving cyclones passing east of the observation site. In connection with Fig. 9 it can be seen that, under those circumstances, initially easterly winds are maintained against the large-scale pressure gradient force by vertical momentum transfer. As seen in Fig. 10, temporary quasigeostrophic winds from north-northeasterly directions then develop just before the stability transition, after which channelled winds from westerly directions are generated initially by the large-scale pressure gradient force against the small easterly flow component of the overlying flow, and subsequently, after about $12 \mathrm{~h}$, also by vertical momentum transfer. 

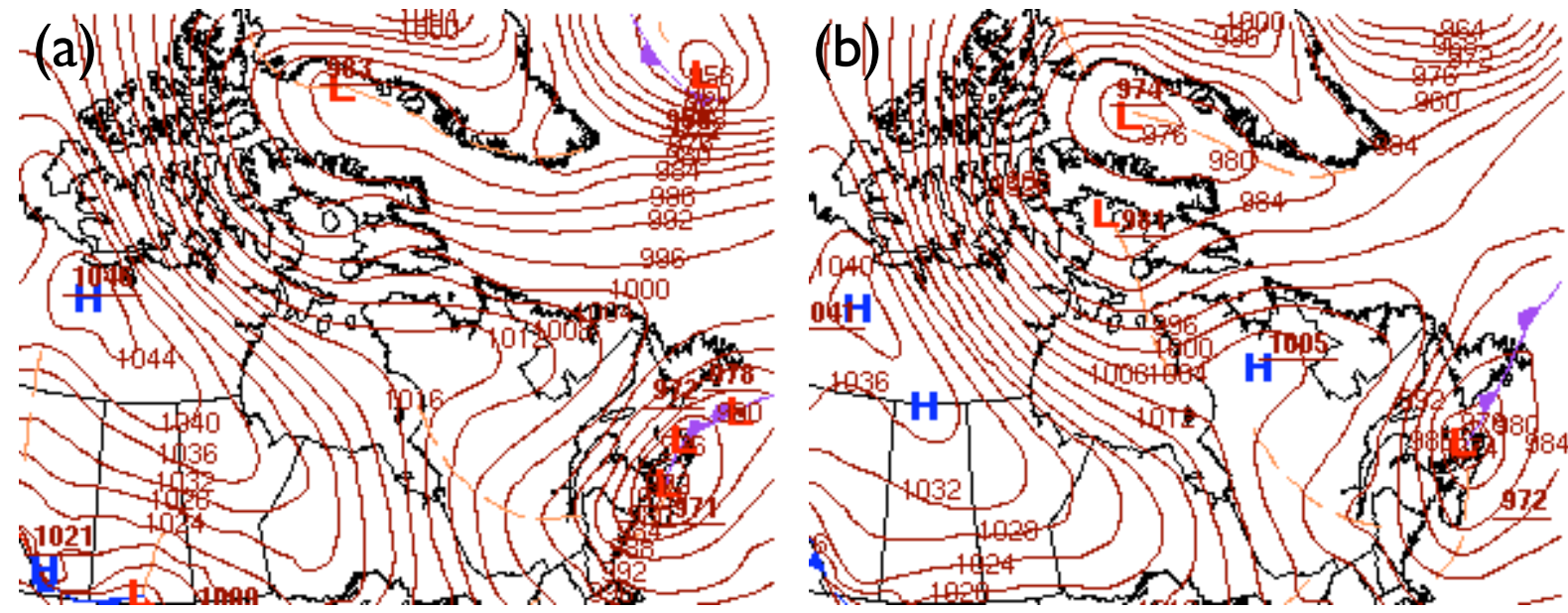

Fig. 12. Surface pressure analyses over eastern Canada on 4 December 2007 at (a) 12 Coordinated Universal Time (UTC), and (b) 21:00 UTC. At 12:00 UTC (07:00 LST), surface winds at Iqaluit are from northwest at 4.2 $\mathrm{m} \mathrm{s}^{-1}$. At 21:00 UTC (16:00 LST), surface winds are from southeast at $3.6 \mathrm{~m} \mathrm{~s}^{-1}$. Surface analyses obtained from Hydrometeorological Prediction Center of the United States National Weather Service.

At Iqaluit, exchanges of large-scale stability from southeasterly to northwesterly wind directions over a 4-day period are most frequently associated with geostrophic winds rapidly backing from south-southeast to north-northwest, suggesting a connection with eastward moving cyclones passing just slightly south of the observation site. As for the wind shifts from easterly to westerly directions at Cape Dorset, there is an exchange in positively active forcing mechanism of channelled winds from along-channel vertical momentum transfer to along-channel large-scale pressure gradients. Due to the location farther east, eastnortheastward moving cyclones passing northwest of Iqaluit, associated with geostrophic winds veering from south to northwest, are more frequently associated with shifts from secondary to primary wind direction than at Cape Dorset. In those cases, at the stability transition, there is an exchange in positively active forcing mechanism from large-scale pressure gradients to vertical momentum transfer.

At both locations, the most frequent transitions from primary to secondary wind direction over a 4-day period occur with geostrophic winds backing from around north to around southeast, typically associated with the passage of a westward tilted ridge located between low-pressure systems over Canada's Northwest Territories and Labrador Sea or Baffin Bay. Less frequently transitions from primary to secondary wind direction are associated with the passage of an inverted ridge and veering surface geostrophic winds, shifting from north-northwest to northeast at Cape Dorset, and from northnortheast to east at Iqaluit.

The persistent northeasterly surface geostrophic wind conditions following shifts to easterly surface winds at Cape Dorset result in extended periods during which the surface flow must be maintained against the large-scale pressure gradient force by strong vertical momentum transfer. These backed surface geostrophic winds, relative to the actual surface winds, have previously been discussed in Sect. 3, in connection with shorter periods of easterly wind conditions. In contrast, at Iqaluit, surface geostrophic winds following shifts to southeasterly surface wind conditions, for the most part remain veered.

An example of the relatively small changes in the largescale surface pressure distribution that may lead to 180degree wind shifts at Iqaluit within a period of a few hours is shown in Fig. 12. In that situation, the local geostrophic wind direction shifts from northwest at 07:00 Local Standard Time (LST) to west-southwest at 16:00 LST, associated with a shift in surface wind direction from northwest to southeast. At 07:00 LST, the large-scale forcing of the surface wind is primarily due to downward momentum transfer. At 16:00 LST, the geostrophic wind is close to its critical direction. The weak to intermediate southeasterly surface wind in that situation is maintained against the overlying flow by the along-channel pressure gradient.

\section{Evolution of surface wind speed}

In the discussion above it was implicitly assumed that channelling occurs along a substantial part of the channel, such that under along-channel wind conditions at the observation sites $c \cdot \nabla \phi=0$ and $\dot{\phi}=\partial_{t} \phi$. As seen in Sect. 7, directional stability of trajectories of the attracting flow, as described by (30), is consistent with the prevailing local wind direction tendencies. However, within channels with varying crosssection or varying type and slope of the bottom surface, wind speed generally shows large variability in the along-channel direction. Qualitatively, the combined magnitude of these effects can therefore be estimated by assuming that locally the along-channel gradient in wind speed vanishes, and by comparing the analytical results of the model based on this 
assumption with the evolution of along-channel wind speed during the 4-day periods centred around large-scale stability transitions discussed in the previous sections.

With $\boldsymbol{c} \cdot \nabla s_{c}=0$ it follows from (25) that

$\frac{\partial s_{c}}{\partial t}+r s_{c}=\sigma$

Locally, the oriented along-channel wind speed is therefore damped by surface drag, and forced by the large-scale stability function. Formally, this differential equation is solved by

$s_{c}(t)=e^{-r\left(t-t_{0}\right)}\left(s_{0}+\int_{t_{0}}^{t} e^{r\left(t^{\prime}-t_{0}\right)} \sigma\left(t^{\prime}\right) d t^{\prime}\right)$,

where $s_{0}=s_{c}\left(t_{0}\right)$ at any reference time $t_{0}$. For simplicity, temporal variations in geostrophic wind speed are neglected, and geostrophic wind direction is assumed to change linearly with time, such that $\phi_{g}(t)=\phi_{g}^{*} \pm \omega\left(t-t_{0}\right)$ and $t_{0}$ represents the time of the stability transition. It then follows from (32) that

$\sigma(t)= \pm \widehat{\sigma} \sin \omega\left(t-t_{0}\right)$

where

$\widehat{\sigma}=\sigma\left(\widehat{\phi}_{g}\right)=s_{g}\left(f \cos \phi_{g}^{*}-q \sin \phi_{g}^{*}\right)$.

Under these assumptions, consistent with the observational results shown in Fig. 10, the large-scale stability function has a sinusoidal time-dependence. Along-channel wind speed is then given by

$$
\begin{aligned}
s_{c}(t)= & \alpha \sin \omega\left(t-t_{0}\right)+\beta \cos \omega\left(t-t_{0}\right) \\
& +\left(s_{0}-\beta\right) e^{-r\left(t-t_{0}\right)},
\end{aligned}
$$

where

$\alpha= \pm \frac{r \widehat{\sigma}}{r^{2}+\omega^{2}}$

and

$\beta=\mp \frac{\omega \widehat{\sigma}}{r^{2}+\omega^{2}}$.

In (38), the magnitude of the transient term $\left(s_{0}-\beta\right) e^{-r\left(t-t_{0}\right)}$ rapidly decreases towards zero starting from any reference time $t_{0} \leq t$, and becomes negligible after only a few hours. Based on the assumptions made, along-channel wind speed therefore locally has a tendency to approach

$s_{\mathrm{LS}}(t)=\alpha \sin \omega\left(t-t_{0}\right)+\beta \cos \omega\left(t-t_{0}\right)$,

which, for a given parameterisation of turbulent momentum transfer and surface drag, depends only on large-scale atmospheric conditions. For the transitions between primary and secondary wind directions shown in Fig. 10, the corresponding ensemble means of the observed along-channel wind components, as well as those calculated based on (41), are shown in Fig. 13.

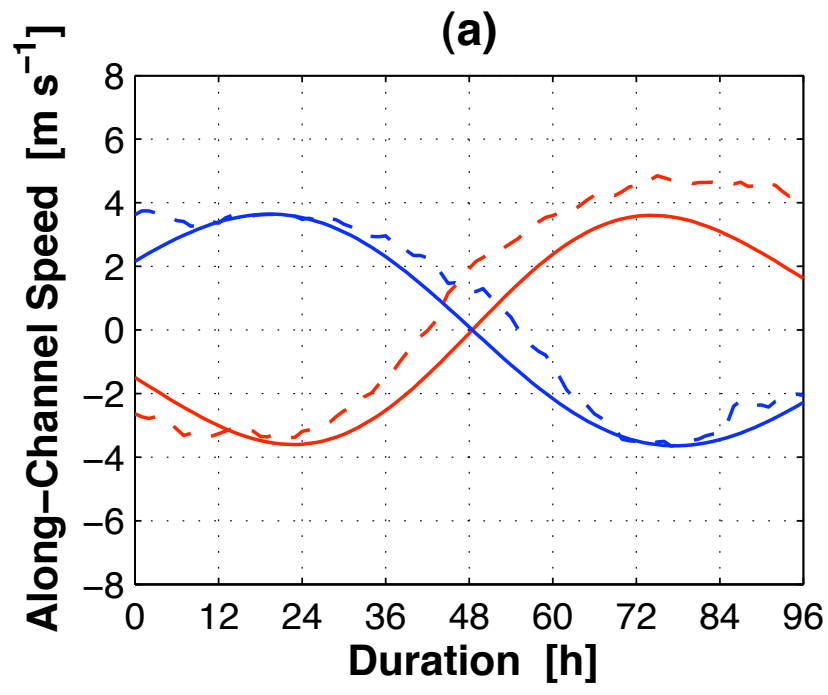

(b)

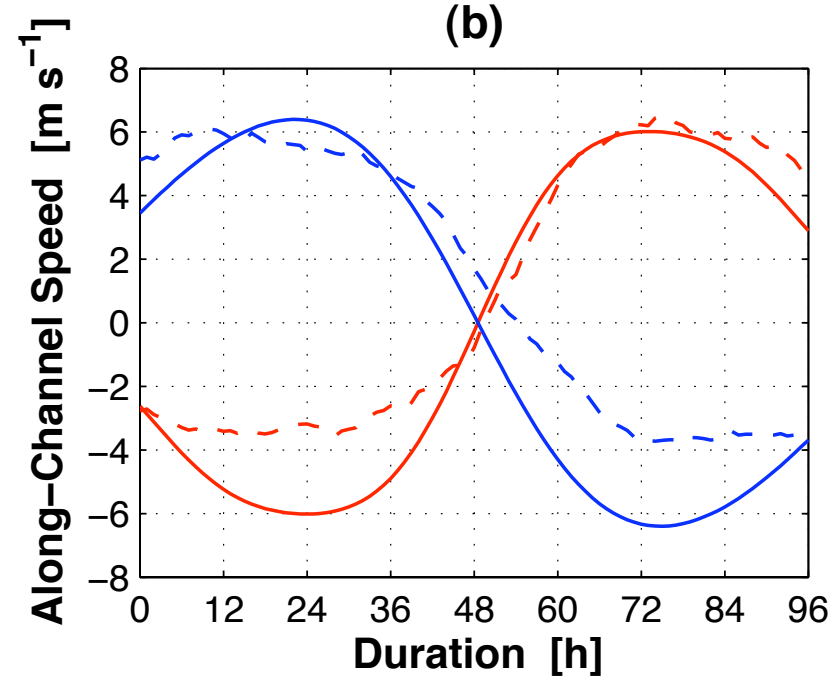

Fig. 13. Ensemble mean evolution of the calculated (solid lines) and actual (dashed lines) along-channel surface wind component at (a) Cape Dorset, and (b) Iqaluit, during transitions across zero of stability function $\sigma$. Red (blue) lines correspond to transitions from secondary (primary) to primary (secondary) wind direction.

For each of the cases, angular frequency $\omega$ is defined as twice the period of time between minimum and maximum of the stability function. At Cape Dorset (Iqaluit), the mean period for transitions from secondary to primary wind direction is $130 \mathrm{~h}(124 \mathrm{~h})$, and $144 \mathrm{~h}(170 \mathrm{~h})$ for transitions from primary to secondary wind direction. At both locations, the latter transition is the slower one.

The amplitude $\widehat{\sigma}$ is defined as the average of the amounts of the minimum and maximum values of $\sigma$ within the 4day transition periods. The mean stability amplitude for both transitions is $0.0024 \mathrm{~m} \mathrm{~s}^{-2}$ at Cape Dorset, and $0.0039 \mathrm{~m} \mathrm{~s}^{-2}$ at Iqaluit. The larger amplitude of stability oscillations at Iqaluit is due to the stronger geostrophic wind speed at that location, as seen in Fig. 7. 
Since the surface drag coefficient $r^{\prime}$ is undetermined, parameter $r=q+r^{\prime}=1.9 q$ at Cape Dorset and $r=1.6 q$ at Iqaluit is chosen such that the calculated peak along-channel wind speeds at least for some periods of channelled flow are consistent with the observations. However, there are some important deviations from the linear dynamics. These are particularly noticeable in the peak speeds of southeasterly winds at Iqaluit, which, relative to northwesterly wind speeds, are overestimated by the linear model. Assuming that these systematic deviations from the linearised large-scale driven dynamics are primarily due to the omission of the nonlinear advection term in (34), it follows that on average $-s_{c} c \cdot \nabla s_{c}>0$, i.e., that at the observation site wind speed typically decreases along trajectories in channelled flow. For onshore southeasterly flow this may be due to the sudden increase in surface drag at the coast, whereas for northwesterly winds emerging from Sylvia Grinnell Valley this may be due to the widening of the channel cross-section and the decrease in the downward surface slope. At Cape Dorset, the westerly flow component following a wind shift from easterly directions is large, not only in comparison with easterly flow, but also with westerly flow prior to a shift to easterly directions. Assuming again that this is primarily due to nonlinear advection, the westerly flow component upstream of the observation site must be particularly large following a shift in local surface wind direction from east to west. This could be explained by the location of the observation site at the downstream end of the channel, together with the northeasterly to northerly overlying large-scale flow, as seen in Fig. 11. During periods of westerly flow prior to wind shifts to easterly directions, the large-scale flow typically has westerly directions as well, thereby reducing positive advection of the westerly flow component towards the observation site.

\section{Conclusions}

In this study, mechanisms involved in the forcing of largescale driven channelled boundary-layer flows at Cape Dorset and Iqaluit were analysed. Both observation sites are lowlying coastal communities located on or near southern Baffin Island, where the prevailing surface wind conditions, and to some degree the general weather conditions, are affected not only by the proximity to the sea, but also by the surrounding topography.

Due to the complex terrain, the as yet unobserved spatial variability of the surface wind around the observation sites is probably substantial. However, directly at the airports, where meteorological measurements are taken, surface winds, particularly at high wind speeds, tend to follow the general orientation of the local topography. Consequently, prevailing surface winds are from two diametrically opposed directions, with a primary surface wind direction from west at Cape Dorset and northwest at Iqaluit, as well as a secondary surface wind direction from east at Cape Dorset and southeast at Iqaluit. Shifts between the two prevailing wind directions can be sudden and may significantly impact the sea state and sea ice conditions, snow drift and accumulation, as well as aviation and other travel safety. This is particularly important at Iqaluit, where shifts between the prevailing wind directions from northwest and southeast are also shifts between offshore and onshore flow.

In combination with local channelling effects, the occurrence of any of the two prevailing wind directions was found to be determined mainly by the direction of the surface geostrophic wind. Shifts between the two prevailing wind directions occur within a narrow range of geostrophic wind directions approximately perpendicular to the orientation of the local terrain. Climatologically, extended periods of channelled winds from both prevailing directions are associated with an initial strengthening of surface winds, from below to above average wind speeds. Conditions for sustained and strong surface winds from a constant along-channel direction, as well as for sudden shifts between the prevailing wind directions, are therefore closely related to the large-scale pressure distribution and in particular to cyclonic weather systems.

It was shown that under channelled wind conditions within a straight valley, a cross-valley balance exists between Coriolis force, horizontal pressure gradients, lateral as well as bottom surface drag, and turbulent momentum transfer. Effective forcing of channelled flow is due to the combined action of the along-channel components of large-scale pressure gradients and vertical momentum transfer from the overlying flow. Due to the quasi-geostrophic nature of the flow immediately above the terrain, these two forcing mechanisms are closely related. Along-channel large-scale pressure gradients and vertical momentum transfer are never maximised at the same time, but may reinforce or counteract each other. The exact balance not only varies with time, but also depends on local terrain features and the boundary-layer stratification.

To quantitatively investigate the role of large-scale pressure gradients in the forcing of high-latitude orographic flow, and to derive criteria for the occurrence of sustained strong winds and sudden wind shifts, a simple two-dimensional dynamical system for the evolution of channelled surface winds was derived from the basic equations of motion. The complexity of the dynamical equations was reduced such that only hourly surface data are required for an implementation of the model. As such, the representation of forcing terms is limited to a three-point calculation of large-scale pressure gradients, and a local parameterisation of turbulent momentum transfer and surface drag.

The resulting dynamical equation for surface wind direction has two coexisting stationary states coinciding with the two prevailing along-channel wind directions. The stability of these stationary states is determined by the surface geostrophic wind direction, which is acting as a slowly varying external parameter. There are two free parameters in the model: vertical momentum transfer coefficient $q$, and surface 
drag coefficient $r$. Of these, $q$ is the more important one, as it affects the stability of stationary wind directions. The coupling parameter $q f^{-1}$, measuring the magnitude of vertical momentum transfer relative to the magnitude of horizontal pressure gradients, is determined such that exchanges in stability between stationary states and sudden wind shifts in the simplified model occur at the critical geostrophic wind directions evident in the long-term wind statistics. Despite the complexity of the definition (24), it was shown that the same value of the coupling parameter applies at both locations, and for shifts from primary to secondary wind direction and vice versa, at both critical geostrophic wind directions. Consistent with the observed increase in surface wind speed during extended periods of channelled flow, the conditions for the stability of stationary along-channel wind directions are identical with the conditions for positive acceleration. The stability analysis therefore provides criteria for strong and persistent, as well as gusty and variable wind conditions, which may be equally hazardous.

It was then shown that the evolution of ensemble-averaged channelled wind directions is modelled by the simplified model, with actual surface winds adjusting to a new stable stationary wind direction within 3-9h. Three independent pressure observations on the same vertical level can therefore be used as predictors of local prevailing wind directions on time-scales of about $6 \mathrm{~h}$ and longer, and stable stationary wind directions of the simplified model can be interpreted as attractors of turbulent channelled flow. On these time-scales it is therefore advantageous to determine the relatively slow evolution of the large-scale pressure distribution, instead of modelling highly variable surface winds directly. The parameterised local wind model thereby offers a tool for empirical downscaling of global climate simulations, and for determining future scenarios for local prevailing wind directions. In particular, it can be used to quantify the sensitivity of surface winds to a changing large-scale pressure distribution, and to investigate local impacts on the prevailing wind directions from changing storm activity. It can be seen in Fig. 3 that at Cape Dorset the prevailing surface geostrophic winds are close to one of the critical directions for which shifts between the prevailing surface wind directions tend to occur. At that location, more so than at Iqaluit, there is therefore the possibility that significant changes in the prevailing local wind conditions may occur due to relatively minor changes in the large-scale atmospheric circulation.

Whereas the local prevailing wind directions and sudden wind shifts are well represented by the simplified dynamical model, wind speed is affected by small-scale geographical variations, such as changes in surface type and channel width, and therefore follows more complex dynamics. Qualitatively, the net effects of these boundary-layer forcing mechanisms are estimated from a comparison of simplified model predictions with the ensemble-mean evolution of along-channel surface wind speed during extended periods of prevailing wind directions, and shifts between them.
At Cape Dorset, there are indications that local timetendencies of along-channel wind speed are affected by the location at the eastern end of the channel, and thus by inhomogeneities in along-channel speed advection. There is the possibility that at the centre of the channel easterly surface winds are better defined than at the eastern end. In that case, the empirical wind model is a better representation of the unobserved flow in the centre of the channel. At Iqaluit it appears as if surface wind speed is not only affected by channelling but also by funnelling effects, as well as by land-sea transitions. The model predictions could be made consistent with the ensemble-mean evolution of along-channel surface wind speed by introducing an inhomogeneous surface drag parameterisation depending on the surface wind direction. However, this is omitted from the present study.

Limitations to the accuracy of model predictions may also arise due to the omission of small-scale thermal effects. At the two locations discussed here, local temperature gradients do not seem to have a significant impact on overall wind statistics. At other locations in the Canadian Archipelago, however, thermal wind systems such as land-sea breezes or anabatic and katabatic winds are known to be important (Hudson et al., 2001). These special wind conditions are decoupled from the ambient flow and must therefore be treated separately from channelled flow driven by the large-scale pressure distribution. Also, the cross-channel force balance may break down, giving rise to occasionally strong crosschannel winds (see Nawri and Stewart (2006) for a climatology of these winds at Iqaluit). These are of critical importance for aviation and must be studied separately.

The exact nature of terrain-induced forcing mechanisms strongly depends on details of the local geography. However, despite significant differences in orientation, length, width, and depth of the orographic channels at Cape Dorset and Iqaluit, qualitatively similar wind conditions are observed at the two locations, as well as similar relationships between actual and geostrophic surface wind directions. A comparison with the results from previous studies shows that these wind conditions are similar to those within some mid-latitude valleys, but are substantially different from others. As long as the prevailing surface wind directions are diametrically opposed, such as is likely to be the case within valleys or along single orographic barriers, the simplified model can be adopted to these different locations by determining the appropriate value of the coupling parameter $q f^{-1}$. Since it only depends on the local wind statistics and large-scale pressure gradients, the model provides a unified mathematical framework for the description of prevailing surface wind conditions at locations with greatly different geographical conditions. In this regard, it is clear from a comparison of the valley geometry at the two locations considered here, that possible similarities in the coupling parameter are not necessarily due to similarities in valley orientation. It is also apparent, that it is neither due to similarities in the absolute values of valley length, width, and depth, nor in the aspect 
ratios of length/width, length/depth, and width/depth. This suggests, that atmospheric boundary-layer stratification, as well as speed and direction relative to the channel orientation of the overlying flow play more important roles. However, more detailed observational and modelling studies are required to be able to draw more definite conclusions.

Acknowledgements. The authors would like to thank ArcticNet, the Natural Sciences and Engineering Research Council of Canada, Environment Canada, and the Institute for Catastrophic Loss Reduction for financial support. Hourly surface data used in this study were obtained from Environment Canada. Sounding data were obtained from the Department of Atmospheric Science of the University of Wyoming.

Edited by:Andreas Baas

Reviewed by: Two anonymous referees

\section{References}

Brümmer, B. and Thiemann, S.: The atmospheric boundary layer in an arctic wintertime on-ice air flow, Bound.-Lay. Meteorol., 104, 53-72, 2002.

Brümmer, B., Kirchgäßner, A., and Müller, G.: The atmospheric boundary layer over Baltic Sea ice, Bound.-Lay. Meteorol., 117, 91-109, 2005.

Drobinski, P., Dabas, A. M., Haeberli, C., and Flamant, P. H.: On the small-scale dynamics of flow splitting in the Rhine Valley during a shallow foehn event, Bound.-Lay. Meteorol., 99, 277296, 2001.

Drobinski, P., Bastin, S., Dusek, J., Zängl, G., and Flamant, P. H.: Flow splitting at the bifurcation between two valleys: Idealized simulations in comparison with Mesoscale Alpine Programme observations, Meteorol. Atmos. Phys., 92, 285-306, 2006.

Eckman, R. M.: Observations and numerical simulations of winds within a broad forested valley, J. Appl. Meteorol., 37, 206-219, 1998.

Ford, J. D., Smit, B., and Wandel, J.: Vulnerability to climate change in the Arctic: A case study from Arctic Bay, Canada, Global Environ. Chang., 16, 145-160, 2006a.
Ford, J. D., Smit, B., Wandel, J., and MacDonald, J.: Vulnerability to climate change in Igloolik, Nunavut: what we can learn from the past and present, Polar Rec., 42, 127-138, 2006 b.

Furger, M.: The radiosoundings of Payerne: Aspects of the synoptic-dynamic climatology of the wind field near mountain ranges, Theor. Appl. Climatol., 45, 3-17, 1992.

Gross, G. and Wippermann, F.: Channeling and countercurrent in the upper Rhine Valley: Numerical simulations, J. Clim. Appl. Meteorol., 26, 1293-1304, 1987.

Henshaw, A.: Winds of change: Weather knowledge amongst the Sikusilarmiut, in: Climate Change: Linking Traditional and Scientific Knowledge, edited by Riewe, R. and Oakes, J., 177186, Aboriginal Issues Press, University of Manitoba, Winnipeg, Manitoba, Canada, 2006.

Hudson, E., Aihoshi, D., Gaines, T., Simard, G., and Mullock, J.: Weather of Nunavut and the Arctic, NAV Canada, Ottawa, Ontario, 246 pp., 2001.

Klaus, D., Mertes, S., and Siegmund, A.: Coherences between upper air flow and channelling mechanism in the Baar Basin, Meteorol. Z., 12, 217-227, 2003.

Laidler, G. and Elee, P.: Sea ice processes and change: Exposure and risk in Cape Dorset, Nunavut, in: Climate Change: Linking Traditional and Scientific Knowledge, edited by Riewe, R. and Oakes, J., 155-175, Aboriginal Issues Press, University of Manitoba, Winnipeg, Manitoba, Canada, 2006.

Monin, A. S. and Yaglom, A. M.: Statistical Fluid Mechanics, Vol 1: Mechanics of Turbulence, MIT Press, Cambridge, Massachusetts, USA, 1971.

Nawri, N. and Stewart, R. E.: Climatological features of orographic low-level jets over Frobisher Bay, Atmos. Ocean, 44, 397-413, 2006.

Reid, S.: Pressure gradients and winds in Cook Strait, Weather Forecast., 11, 476-488, 1996.

Weber, R. O. and Kaufmann, P.: Relationship of synoptic winds and complex terrain flows during the MISTRAL field experiment, J. Appl. Meteorol., 37, 1486-1496, 1998.

Whiteman, C. D. and Doran, J. C.: The relationship between overlying synoptic-scale flows and winds within a valley, J. Appl. Meteorol., 32, 1669-1682, 1993.

Whiteman, C. D., Zhong, S., and Bian, X.: Wintertime boundary layer structure in the Grand Canyon, J. Appl. Meteorol., 38, 1084-1102, 1999. 